Check for updates

Cite this: RSC Adv., 2018, 8, 29464

Received 24th July 2018

Accepted 14th August 2018

DOI: $10.1039 / c 8 r a 06262 e$

rsc.li/rsc-advances

\section{Synthesis of well-defined star, star-block, and miktoarm star biodegradable polymers based on PLLA and PCL by one-pot azide-alkyne click reaction}

\begin{abstract}
Xiaoqi Yan, Jianbo Li ${ }^{*}{ }^{*}$ and Tianbin Ren
Based on the "arm-first" strategy, ring-opening polymerization (ROP) and one-pot azide-alkyne click reaction, well-defined star-shaped polymers with different architectures have been successfully synthesized, including the star homopolymers four-arm star-shaped polycaprolactone $(4 \mathrm{sPCL})$ and fourarm star-shaped poly(L-lactic acid) (4sPLLA), star-block copolymer 4sPCL-b-PLLA and miktoarm starshaped copolymer PCL ${ }_{2} \mathrm{PLLA}_{2}$. The star homopolymers 4sPCL and 4sPLLA were synthesized by a click reaction of an azide small molecule initiator and $\mathrm{HC} \equiv \mathrm{C}-\mathrm{PCL}$ or $\mathrm{HC} \equiv \mathrm{C}$-PLLA. The star-block copolymer 4 SPCL- $b$-PLLA was synthesized by a click reaction of an azide small molecule initiator and the block copolymer $\mathrm{HC} \equiv \mathrm{C}-\mathrm{PCL}-b$-PLLA. The miktoarm star polymer $\mathrm{PCL}_{2} \mathrm{PLLA}_{2}$ was synthesized by a one-pot azide-alkyne click reaction of simultaneous addition of equal proportions of $\mathrm{HC} \equiv \mathrm{C}-\mathrm{PCL}$ and $\mathrm{HC} \equiv \mathrm{C}$ PLLA. The structures of these star-shaped polymers have been confirmed by NMR, FT-IR and GPC. Furthermore, the melting and crystallization behaviors investigated using DSC and WXRD also confirm the formation of star-shaped polymers with different architectures.
\end{abstract}

\section{Introduction}

Star polymers have unique topological structures with at least three macromolecular chains (arms) radiating from a central core. Miktoarm star polymers (sometimes called asymmetric star polymers, heteroarm star polymers, or simply miktoarm polymers) are star-shaped polymers where any number of various types of polymer arms emanate from a core. ${ }^{1}$ Atoms, small molecules, branched macromolecules, nanogels and nanoparticles can all be used as central cores. Compared to linear polymers, star polymers have low dilute solution viscosity, encapsulation ability, inner and peripheral functions, and enhancement. ${ }^{2-4}$ Thus, star polymers have been exploited in adhesives, flocculants, and lubricants for oils in the automotive industry. In addition, the use of star polymers in drug delivery devices and as self-adjuvanting vaccines has opened exciting new biomedical applications. ${ }^{5}$ The preparation of defined polymers with a narrow molecular weight distribution structure is very important to establish a structure-performance relationship, so the synthesis of star polymers has a significant meaning in theoretical and practical applications. ${ }^{2,6-10}$

Institute of Nano and Biopolymeric Materials, School of Materials Science and Engineering, Key Laboratory of Advanced Civil Engineering Materials, Ministry of Education, Tongji University, 4800 Caoan Road, Shanghai 201804, China. E-mail: lijianbo@tongji.edu.cn; Fax: +86-21-33515906; Tel: +86-21-33515906
Star or star-shaped polymers have been efficiently, precisely, and widely synthesized along with developments in various living polymerizations, such as living anionic, ${ }^{\mathbf{1 1 - 1 3}}$ cationic ${ }^{14,15}$ and radical polymerizations. ${ }^{16,17}$ In particular, with the development of reactive/controlled radical polymerization technologies such as reversible addition-fragmentation chain transfer (RAFT) polymerization, ${ }^{5,18}$ atom transfer radical polymerization (ATRP) ${ }^{19}$ and nitrogen-oxygen stable radical polymerization (NMP), ${ }^{20}$ the synthesis of a well-defined star polymer is much easier recently. During the past few years, various poly(meth)acrylates, poly(meth)acrylamides, polystyrenes, and polyacrylonitrile were successfully prepared by ATRP with relatively narrow molecular weight distribution $\left(M_{\mathrm{w}} / M_{\mathrm{n}}, M_{\mathrm{WD}}\right)$ and targeted degrees of polymerization (DP). ${ }^{19}$

For synthetic route, star polymers can usually be synthesized in two ways, the "core-first" and the "arm-first". The "core-first" strategy uses a multi-functional initiator to initiate polymerization of the monomer, and each arm grows from inside to out. The number of arms and the composition of the arms are determined by the structure of the initiator. ${ }^{21,22}$ The "arm-first" strategy means that a linear polymer chain is synthesized firstly as an arm and then reacted by a coupling agent with a multifunctional group. The polymer arms synthesized by this method are equal in length, but the number of arms usually has a statistical distribution. ${ }^{23}$ Therefore, when adopting "arm-first" strategy, it is required to select an efficient macromolecular coupling technology to 


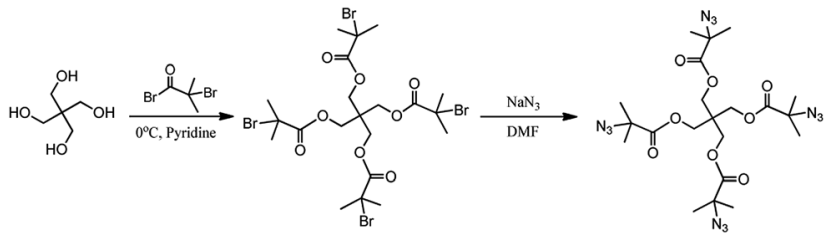

Scheme 1 Synthetic route of the azide small molecule initiator.

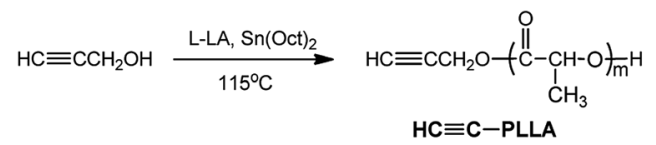

$\left.\mathrm{HC} \equiv \mathrm{CCH}_{2} \mathrm{OH} \underset{\text { Toluene, } 110^{\circ} \mathrm{C}}{\stackrel{\mathrm{CL}, \mathrm{Sn}(\mathrm{Oct})_{2}}{\longrightarrow}} \mathrm{HC} \equiv \mathrm{CCH}_{2} \mathrm{O}+\stackrel{\mathrm{O}}{\mathrm{C}}-\mathrm{CH}_{2} \mathrm{CH}_{2} \mathrm{CH}_{2} \mathrm{CH}_{2} \mathrm{CH}_{2} \mathrm{O}\right)_{\mathrm{n}} \mathrm{H}$<smiles>C#CCCCCCOC(=O)C(C)(O)C(=O)OCCCCCC(=O)OCC#C</smiles>

Scheme 2 Synthetic route of the alkynyl terminated poly(lactic acid) and polycaprolactone prepolymer.

ensure the controllability of the number of arms. The click reaction has many characteristics such as rapid reaction, high yield, mild reaction conditions, good chemical compatibility, and is widely used in the field of polymers. ${ }^{24-33}$ In recent years, the 1,3-dipolar cycloaddition click reaction has been widely used in functional chemistry and macromolecular modification in polymer chemistry. The introduction of this technology into the synthesis of star polymers can enable the simple and efficient synthesis of special-structured star copolymers (such as miktoarm star copolymers).

Poly(L-lactic acid) (PLLA) and polycaprolactone (PCL) are two kinds of polymer, which have excellent biodegradability, biocompatibility and processability. Therefore, the research and development of their materials and products have always been a focus of concern in the scientific community in various countries. ${ }^{34}$ So far, a large number of PLLA and PCL star copolymers that have different arm numbers, chemical compositions and chain topological structures have been synthesized. ${ }^{35-41}$

In this paper, star-shaped polymers with different architectures have been successfully prepared by the "arm-first" strategy and the combination of ring-opening polymerization (ROP) and click chemistry. The synthetic strategy and route was as shown in Schemes 1-3. The structures of star-shaped polymers are characterized by NMR, FT-IR and GPC. The melting and crystallization behaviors of these star-shaped polymers were investigated by DSC and WXRD.
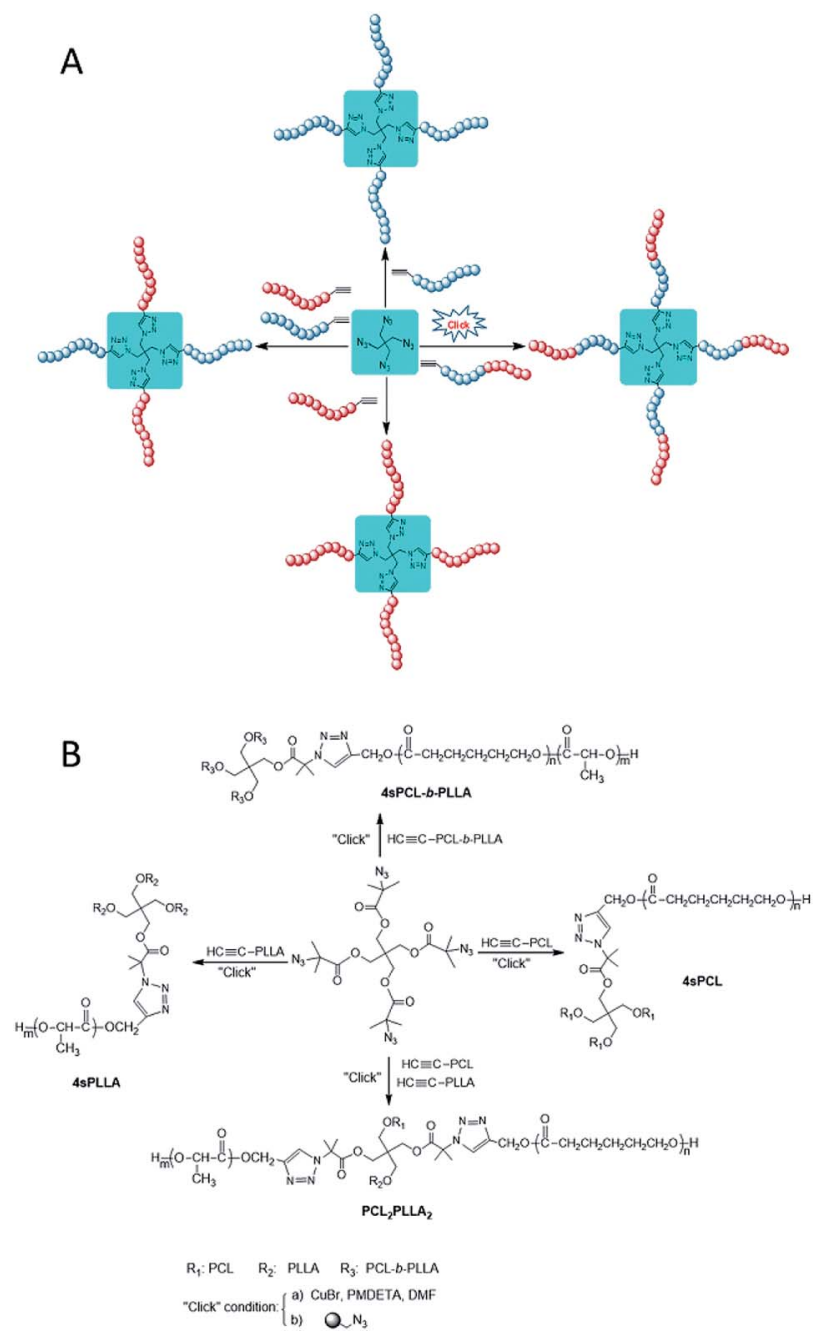

Scheme 3 Synthetic strategy (A) and route (B) of star, star-block, and miktoarm star polymers by one-pot azide-alkyne click reaction.

\section{Experimental}

\subsection{Materials}

Propargyl alcohol (99\%; Shanghai Jing-Chun Co., Ltd.) was dried over anhydrous magnesium sulfate, then was distilled under reduced pressure. Methylbenzene and tetrahydrofuran were refluxed by sodium metal and distilled under ordinary pressure before use. $\varepsilon$-Caprolactone (CL, 99\%; Acros Organic) was distilled over $\mathrm{CaH}_{2}$ and stored under $\mathrm{N}_{2}$ before use. L-Lactide (LLA; Shanghai Tong-Jie-Liang Biomaterials Co., Ltd.) was purified by twice recrystallization from ethyl acetate and dried in a vacuum at room temperature. Tin 2-ethylhexanoate (Sn $(\mathrm{Oct})_{2}$; Aldrich, USA $)$ was distilled under reduced pressure before use. Cuprous bromide ( $\mathrm{CuBr}, \geq 98.5 \%$ ) was wash to colorless with acetic acid, washed three times with anhydrous ethanol and anhydrous ether and dried in a vacuum. Sodium nitride $\left(\mathrm{NaN}_{3}, 99 \%\right.$; Shanghai Jing-Chun Co., Ltd.), 2-bromoisobutyryl bromide (97\%; Alfa Aesar, UK) and $N, N, N^{\prime}, N^{\prime}, N^{\prime \prime}$-pentamethyldiethylene triamine (PMDETA, 98\%; Alfa Aesar, UK) and Merrifield resin (BR; Shanghai Ju-Yuan Biomaterials Co., 
Ltd.) were used as received without further purification. Pentaerythritol (PENTA, $\geq 99 \%$; Aldrich, USA) was dried in a vacuum at $60{ }^{\circ} \mathrm{C}$. Pyridine was distilled over $\mathrm{KOH}$ before use. All other chemicals were of analytical grade, and purchased from Sinopharm Chemical Regent Company.

\subsection{Preparation of Merrifield's resin-azide}

Brief procedure for the preparation of Merrifield's resin-azide was as follows. ${ }^{42}$ The Merrifield's resin $\left(5.0 \mathrm{~g}, 1.6 \mathrm{mmol} \mathrm{g}^{-1}\right.$, $8 \mathrm{mmol} \mathrm{Cl})$ and $\mathrm{NaN}_{3}(5.2 \mathrm{~g}, 80 \mathrm{mmol})$ were added in $200 \mathrm{~mL}$ of $\mathrm{DMF}$ and the resulting mixture was stirred at $50{ }^{\circ} \mathrm{C}$ for $48 \mathrm{~h}$. The obtained resin was washed with water and THF three times, and dried at $40{ }^{\circ} \mathrm{C}$ in a vacuum oven to constant weight.

IR (KBr): $2095 \mathrm{~cm}^{-1}\left(-\mathrm{N}_{3}\right)$.

\subsection{Synthesis of 2-bromoisobutyrate pentaerythritol (PENTA-Br)}

Pentaerythritol (1.36 g, $10 \mathrm{mmol})$, freshly distilled pyridine $(5 \mathrm{~mL})$ and dried magnetics were added into thoroughly dried THF (50 $\mathrm{mL}$ ) and were stirred and dissolved at room temperature. A solution of 2-bromoisobutyryl bromide (11.49 $\mathrm{g}, 50 \mathrm{mmol}$ ) and THF (10 mL) was slowly added dropwise to the resulting mixture at $0{ }^{\circ} \mathrm{C}$ in an ice water bath, and then stirred at room temperature for $24 \mathrm{~h}$. After reacting completely, the precipitate of the pyridinium salt was filtered off, and the THF is spin-dried. Trichloromethane $(50 \mathrm{~mL})$ was added in order to dissolve product, washed first with $5 \% \mathrm{NaHCO}_{3}(100 \mathrm{~mL} \times 3)$ and then with deionized water $(100 \mathrm{~mL} \times 3)$; the organic phases were combined and dried over anhydrous $\mathrm{MgSO}_{4}$ overnight. After filtration, the trichloromethane was spin-dried, a white crude product was recrystallized three times in vacuo and dried under vacuum.

${ }^{1} \mathrm{H}$ NMR $\left(\mathrm{CDCl}_{3}, \delta, \mathrm{ppm}\right): 4.33\left(2 \mathrm{H}, \mathrm{CH}_{2} \mathrm{O}\right.$ in PENTA), 1.94 $\left(6 \mathrm{H}, \mathrm{CH}_{3}\right.$ in the BiBB group). IR $\left(\mathrm{cm}^{-1}\right): 3008,2980,2925,2862$, 1730, 1465, 1387, 1366, 1268, 1163, 1099, 1008, 980, 938, 917, $854,756,644,602$.

\subsection{Synthesis of 2-azido pentaerythritol isobutyrate (PENTA-N $\left.\mathbf{N}_{3}\right)$}

Pentaerythritol 2-bromoisobutyrate ( $4 \mathrm{~g}, 5.46 \mathrm{mmol}$ ) and sodium azide $(7.1 \mathrm{~g}, 109.2 \mathrm{mmol})$ were added to DMF (50 mL), and were stirred at $80{ }^{\circ} \mathrm{C}$ for two days. After reacting completely, the excess $\mathrm{NaN}_{3}$ was filtered off. The solvent was distilled off under reduced pressure, then chloroform was added to dissolve the product and the resulting mixture was extracted three times with deionized water to remove the remaining $\mathrm{NaN}_{3}$. The organic layer was dried over anhydrous magnesium sulfate. The product was recrystallized three times with absolute ethanol.

${ }^{1} \mathrm{H}$ NMR $\left(\mathrm{CDCl}_{3}, \delta, \mathrm{ppm}\right): 4.28\left(2 \mathrm{H}, \mathrm{CH}_{2} \mathrm{O}\right.$ in PENTA), 1.49 $\left(6 \mathrm{H}, \mathrm{CH}_{3}\right.$ in the azide-BiBB group). IR $\left(\mathrm{cm}^{-1}\right): 2980,2938,2904$, 2875, 2097, 1730, 1464, 1366, 1254, 1142, 980, 924, 882, 812, $763,657,615,580$.

\subsection{Synthesis of the alkynyl terminated polycaprolactone $(\mathbf{H C} \equiv \mathbf{C}-\mathbf{P C L})$}

The alkynyl terminated polycaprolactone (HC $\equiv \mathrm{C}-\mathrm{PCL})$ was prepared by the ROP of $\varepsilon$-caprolactone with propargyl alcohol as a small molecule initiator. The synthesis of $\mathrm{HC} \equiv \mathrm{C}-\mathrm{PCL}$ was as follows: $\varepsilon$-caprolactone $(2.854 \mathrm{~g}, 25 \mathrm{mmol})$, propynyl alcohol $(0.070 \mathrm{~g}, 1.25 \mathrm{mmol})$, catalytic amount of $\mathrm{Sn}(\mathrm{Oct})_{2}$ and thoroughly dried toluene $(20 \mathrm{~mL})$ were successively added into a polymerization tube. After three cycles of vacuum-nitrogen filling, the polymerization tube was placed in a $110{ }^{\circ} \mathrm{C}$ oil bath for 24 hours under nitrogen protection. The obtained product was dissolved with chloroform and then precipitated twice in methanol. The product after suction filtration was dried in vacuum at room temperature to constant weight. The conversion rate is calculated by the weighing method.

$M_{\mathrm{n}, \mathrm{NMR}}=2290, M_{\mathrm{n}, \mathrm{GPC}}=2350, M_{\mathrm{w}} / M_{\mathrm{n}}=1.17 .{ }^{1} \mathrm{H} \mathrm{NMR}$ $\left(\mathrm{CDCl}_{3}, \delta, \mathrm{ppm}\right): 4.68\left(2 \mathrm{H}, \mathrm{CH}_{2} \mathrm{O}\right.$ in alkyne group), $4.06(2 \mathrm{H}$, $\mathrm{CH}_{2} \mathrm{O}$ in PCL), $3.65\left(2 \mathrm{H}\right.$, terminal $\mathrm{CH}_{2} \mathrm{O}$ in PCL), $2.47(1 \mathrm{H}$, $-\mathrm{C} \equiv \mathrm{CH}$ in alkyne group), $2.31\left(2 \mathrm{H}, \mathrm{COCH}_{2}\right.$ in $\left.\mathrm{PCL}\right), 1.65(4 \mathrm{H}$, $\mathrm{CH}_{2}$ in PCL), 1.39 (2H, $\mathrm{CH}_{2}$ in PCL). IR $\left(\mathrm{cm}^{-1}\right): 3556,3436,3265$, 2946, 2859, 1729, 1471, 1422, 1372, 1296, 1233, 1169, 1106, 1043, 959, 728.

\subsection{Synthesis of the alkynyl terminated poly(lactic acid) (HC $\equiv$ C-PLLA)}

The alkynyl terminated poly(lactic acid) (HC $\equiv$ C-PLLA) was prepared by the ROP of L-lactide with propargyl alcohol as a small molecule initiator. The synthesis of $\mathrm{HC} \equiv \mathrm{C}$-PLLA was as follows: L-lactide $(3.603 \mathrm{~g}, 25 \mathrm{mmol})$, propynyl alcohol $(0.070 \mathrm{~g}$, $1.25 \mathrm{mmol}$ ) and catalytic amount of $\mathrm{Sn}(\mathrm{Oct})_{2}$ were successively added into a polymerization tube. After three cycles of vacuumnitrogen filling, the polymerization tube was placed in a $115{ }^{\circ} \mathrm{C}$ oil bath for 24 hours under nitrogen protection. The obtained product was dissolved with chloroform and then precipitated twice in methanol. The product after suction filtration was dried in vacuum at room temperature to constant weight. The conversion rate is calculated by the weighing method.

$M_{\mathrm{n}, \mathrm{NMR}}=2800, M_{\mathrm{n}, \mathrm{GPC}}=2950, M_{\mathrm{w}} / M_{\mathrm{n}}=1.21 .{ }^{1} \mathrm{H} \mathrm{NMR}$ $\left(\mathrm{CDCl}_{3}, \delta, \mathrm{ppm}\right): 5.17(1 \mathrm{H}, \mathrm{CHO}$ in PLLA $), 4.72\left(2 \mathrm{H}, \mathrm{CH}_{2} \mathrm{O}\right.$ in alkyne group), 4.35 (1H, terminal CHO in PLLA), $2.50(1 \mathrm{H}$, $-\mathrm{C} \equiv \mathrm{CH}$ in alkyne group), $1.58\left(3 \mathrm{H}, \mathrm{CH}_{3}\right.$ in PLLA). IR $\left(\mathrm{cm}^{-1}\right)$ : 3650, 3550, 3250, 2996, 2945, 1756, 1455, 1387, 1360, 1209, 1183, 1135, 1094, 1046, 869, 760, 691.

\subsection{Synthesis of the alkynyl terminated block copolymer (HC $\equiv$ C-PCL- $b$-PLLA)}

The alkynyl terminated block copolymer (HC $\equiv \mathrm{C}-\mathrm{PCL}-b$-PLLA) was prepared by the ROP of L-lactide with $\mathrm{HC} \equiv \mathrm{C}-\mathrm{PCL}$ as macroinitiator. The synthesis of $\mathrm{HC} \equiv \mathrm{C}-\mathrm{PCL}-b$-PLLA was as follows: L-lactide (0.865 g, $6 \mathrm{mmol}), \mathrm{HC} \equiv \mathrm{C}-\mathrm{PCL}(0.69 \mathrm{~g}, 0.3 \mathrm{mmol})$ and catalytic amount of $\mathrm{Sn}(\mathrm{Oct})_{2}$ were successively added into a polymerization tube. After three cycles of vacuum-nitrogen filling, the polymerization tube was placed in a $115{ }^{\circ} \mathrm{C}$ oil bath for 24 hours under nitrogen protection. The obtained product was dissolved with chloroform and then precipitated twice in methanol. The product after suction filtration was dried in vacuum at room temperature to constant weight. The conversion rate is calculated by the weighing method.

$M_{\mathrm{n}, \mathrm{NMR}}=5100, M_{\mathrm{n}, \mathrm{GPC}}=5160, M_{\mathrm{w}} / M_{\mathrm{n}}=1.20 .{ }^{1} \mathrm{H} \mathrm{NMR}$ $\left(\mathrm{CDCl}_{3}, \delta, \mathrm{ppm}\right): 5.17(1 \mathrm{H}, \mathrm{CHO}$ in PLLA $), 4.68\left(2 \mathrm{H}, \mathrm{CH}_{2} \mathrm{O}\right.$ in 
alkyne group), 4.37 (1H, terminal CHO in PLLA), $4.06\left(2 \mathrm{H}, \mathrm{CH}_{2} \mathrm{O}\right.$ in PCL), $2.47\left(1 \mathrm{H},-\mathrm{C} \equiv \mathrm{CH}\right.$ in alkyne group), $2.31\left(2 \mathrm{H}, \mathrm{COCH}_{2}\right.$ in PCL), 1.65 (4H, $\mathrm{CH}_{2}$ in PCL), 1.58 (3H, $\mathrm{CH}_{3}$ in PLLA), $1.39(2 \mathrm{H}$, $\mathrm{CH}_{2}$ in PCL). IR $\left(\mathrm{cm}^{-1}\right): 3430-3560,2995,2947,2865,1756$, 1729, 1453, 1362, 1293, 1245, 1182, 1134, 1086, 1044, 961, 871, 760, 733, 692, 582 .

\subsection{Synthesis of four-arm star polycaprolactone (4SPCL)}

The synthesis of $4 \mathrm{sPCL}$ was as follows. PENTA-N ${ }_{3}(87.1 \mathrm{mg}$, $0.15 \mathrm{mmol}, 0.6 \mathrm{mmol}-\mathrm{N}_{3}$ group), $\mathrm{HC} \equiv \mathrm{C}-\mathrm{PCL}$ (1.6 g, $\left.0.7 \mathrm{mmol}\right)$ and DMF $(30 \mathrm{~mL})$ were added into a round bottom flask. After dissolution was complete, the solution was sparged with nitrogen for $15 \mathrm{~min}$, then $\mathrm{CuBr}(86.1 \mathrm{mg}, 0.6 \mathrm{mmol})$ and PMDETA (104 mg, $0.6 \mathrm{mmol}$ ) were added. The mixture in the flask was degassed by three freeze-vacuum-thaw cycles. Then, nitrogen gas was introduced into the flask and the flask was immersed into an oil bath at $60{ }^{\circ} \mathrm{C}$ for $48 \mathrm{~h}$. After the reaction was carried out for prescribed time, the flask was rapidly cooled to room temperature by ice water. The Merrifield's resin-azide ( $0.3 \mathrm{~g}, 0.48 \mathrm{mmol}-\mathrm{N}_{3}$ group) was added into the flask. The mixture in the flask was degassed by three freeze-vacuum-thaw cycles. Then, nitrogen gas was introduced into the flask and the flask was immersed into an oil bath at $60{ }^{\circ} \mathrm{C}$ for $24 \mathrm{~h}$. The polymer solution was passed through a short column of neutral alumina to remove the metal salt and Merrifield's resin-azide. After the polymer solution was concentrated, it was precipitated in methyl alcohol. The product after suction filtration was dried in vacuum at room temperature to constant weight. The conversion rate is calculated by the weighing method.

$M_{\mathrm{n}, \mathrm{NMR}}=9910, M_{\mathrm{n}, \mathrm{GPC}}=6320, M_{\mathrm{w}} / M_{\mathrm{n}}=1.15 .{ }^{1} \mathrm{H} \mathrm{NMR}$ $\left(\mathrm{CDCl}_{3}, \delta, \mathrm{ppm}\right): 7.78(1 \mathrm{H}, \mathrm{CH}$ in triazole ring $), 5.22\left(2 \mathrm{H},-\mathrm{CH}_{2} \mathrm{O}\right.$ conjoint to the triazole ring), $4.20\left(2 \mathrm{H}, \mathrm{CH}_{2} \mathrm{O}\right.$ in PENTA initiator), $4.06\left(2 \mathrm{H}, \mathrm{CH}_{2} \mathrm{O}\right.$ in $\left.\mathrm{PCL}\right), 3.64\left(2 \mathrm{H}\right.$, terminal $\mathrm{CH}_{2} \mathrm{O}$ in $\left.\mathrm{PCL}\right)$, $2.31\left(2 \mathrm{H}, \mathrm{COCH}_{2}\right.$ in PCL), $1.95\left(6 \mathrm{H},-\mathrm{CH}_{3}\right.$ in the $\mathrm{BiBB}$ group), 1.64 (4H, $\mathrm{CH}_{2}$ in PCL), 1.38 (2H, $\mathrm{CH}_{2}$ in PCL). IR ( $\left.\mathrm{cm}^{-1}\right): 3430-$ 3560, 2943, 2865, 1729, 1469, 1420, 1396, 1367, 1293, 1240, 1180, 1108, 1047, 964, 933, 837, 735, 705.

\subsection{Synthesis of four-arm star poly(lactic acid) (4sPLLA)}

The synthesis of 4sPLLA was as follows. PENTA-N ${ }_{3}(87.1 \mathrm{mg}$, $0.15 \mathrm{mmol}, 0.6 \mathrm{mmol}-\mathrm{N}_{3}$ group), $\mathrm{HC} \equiv \mathrm{C}-\mathrm{PLLA}(2.0 \mathrm{~g}, 0.71$ $\mathrm{mmol}$ ) and DMF (30 mL) were added into a round bottom flask. After dissolution was complete, the solution was sparged with nitrogen for $15 \mathrm{~min}$, then $\mathrm{CuBr}(86.1 \mathrm{mg}, 0.6 \mathrm{mmol})$ and PMDETA (104 mg, $0.6 \mathrm{mmol}$ ) were added. The mixture in the flask was degassed by three freeze-vacuum-thaw cycles. Then, nitrogen gas was introduced into the flask and the flask was immersed into an oil bath at $60{ }^{\circ} \mathrm{C}$ for $48 \mathrm{~h}$. After the reaction was carried out for prescribed time, the flask was rapidly cooled to room temperature by ice water. The Merrifield's resin-azide ( $0.3 \mathrm{~g}, 0.48 \mathrm{mmol}-\mathrm{N}_{3}$ group) was added into the flask. The mixture in the flask was degassed by three freeze-vacuum-thaw cycles. Then, nitrogen gas was introduced into the flask and the flask was immersed into an oil bath at $60{ }^{\circ} \mathrm{C}$ for $24 \mathrm{~h}$. The polymer solution was passed through a short column of neutral alumina to remove the metal salt and Merrifield's resin-azide.
After the polymer solution was concentrated, it was precipitated in methyl alcohol. The product after suction filtration was dried in vacuum at room temperature to constant weight. The conversion rate is calculated by the weighing method.

$M_{\mathrm{n}, \mathrm{NMR}}=12500, M_{\mathrm{n}, \mathrm{GPC}}=8750, M_{\mathrm{w}} / M_{\mathrm{n}}=1.21 .{ }^{1} \mathrm{H} \mathrm{NMR}$ $\left(\mathrm{CDCl}_{3}, \delta, \mathrm{ppm}\right): 7.78\left(1 \mathrm{H}, \mathrm{CH}\right.$ in triazole ring), $5.31\left(2 \mathrm{H},-\mathrm{CH}_{2} \mathrm{O}\right.$ conjoint to the triazole ring), $5.16(1 \mathrm{H}, \mathrm{CHO}$ in PLLA $), 4.35(1 \mathrm{H}$, terminal $\mathrm{CHO}$ in PLLA), 4.21 (2H, $\mathrm{CH}_{2} \mathrm{O}$ in PENTA initiator), $1.95\left(6 \mathrm{H},-\mathrm{CH}_{3}\right.$ in the BiBB group), $1.58\left(3 \mathrm{H}, \mathrm{CH}_{3}\right.$ in PLLA). IR $\left(\mathrm{cm}^{-1}\right):$ 3450-3560, 2997, 2950, 2870, 1756, 1456, 1385, 1360, 1210, 1186, 1132, 1090, 1042, 921, 867, 753, 733, 716, 693.

\subsection{Synthesis of four-arm star block copolymer (4sPCL- $b$ - PLLA)}

The synthesis of 4 sPCL- $b$-PLLA was as follows. PENTA-N ${ }_{3}$ (46.4 mg, $0.08 \mathrm{mmol}, 0.32 \mathrm{mmol}-\mathrm{N}_{3}$ groups), HC$\equiv \mathrm{C}-\mathrm{PCL}-b$ PLLA (2.1 g, $0.41 \mathrm{mmol})$ and DMF $(35 \mathrm{~mL})$ were added into a round bottom flask. After dissolution was complete, the solution was sparged with nitrogen for $15 \mathrm{~min}$, then $\mathrm{CuBr}$ (46 mg, $0.32 \mathrm{mmol}$ ) and PMDETA (56 mg, $0.32 \mathrm{mmol}$ ) were added. The mixture in the flask was degassed by three freezevacuum-thaw cycles. Then, nitrogen gas was introduced into the flask and the flask was immersed into an oil bath at $60^{\circ} \mathrm{C}$ for $48 \mathrm{~h}$. After the reaction was carried out for prescribed time, the flask was rapidly cooled to room temperature by ice water. The Merrifield's resin-azide ( $0.3 \mathrm{~g}, 0.48 \mathrm{mmol}-\mathrm{N}_{3}$ group) was added into the flask. The mixture in the flask was degassed by three freeze-vacuum-thaw cycles. Then, nitrogen gas was introduced into the flask and the flask was immersed into an oil bath at $60{ }^{\circ} \mathrm{C}$ for $24 \mathrm{~h}$. The polymer solution was passed through a short column of neutral alumina to remove the metal salt and Merrifield's resin-azide. After the polymer solution was concentrated, it was precipitated in methyl alcohol. The product after suction filtration was dried in vacuum at room temperature to constant weight. The conversion rate is calculated by the weighing method.

$M_{\mathrm{n}, \mathrm{NMR}}=19030, M_{\mathrm{n}, \mathrm{GPC}}=12600, M_{\mathrm{w}} / M_{\mathrm{n}}=1.18 .{ }^{1} \mathrm{H} \mathrm{NMR}$ $\left(\mathrm{CDCl}_{3}, \delta, \mathrm{ppm}\right): 7.79\left(1 \mathrm{H}, \mathrm{CH}\right.$ in triazole ring), $5.22\left(2 \mathrm{H},-\mathrm{CH}_{2} \mathrm{O}\right.$ conjoint to the triazole ring), $5.18(1 \mathrm{H}, \mathrm{CHO}$ in PLLA), $4.35(1 \mathrm{H}$, terminal $\mathrm{CHO}$ in PLLA), 4.21 (2H, $\mathrm{CH}_{2} \mathrm{O}$ in PENTA initiator), $4.06\left(2 \mathrm{H}, \mathrm{CH}_{2} \mathrm{O}\right.$ in PCL), $2.31\left(2 \mathrm{H}, \mathrm{COCH}_{2}\right.$ in PCL), $1.94(6 \mathrm{H}$, $-\mathrm{CH}_{3}$ in the BiBB group), $1.64\left(4 \mathrm{H}, \mathrm{CH}_{2}\right.$ in PCL), $1.58\left(3 \mathrm{H}, \mathrm{CH}_{3}\right.$ in PLLA), 1.38 (2H, $\mathrm{CH}_{2}$ in PCL). IR ( $\left.\mathrm{cm}^{-1}\right)$ : 3430-3560, 2997, 2943, 2865, 1756, 1729, 1453, 1385, 1360, 1270, 1210, 1180, 1132, 1083, 1042, 961, 867, 735, 705.

\subsection{Synthesis of "One-pot" hetero-arm star copolymer $\left(\mathbf{P C L}_{2}\right.$ PLLA $\left._{2}\right)$}

The synthesis of $\mathrm{PCL}_{2} \mathrm{PLLA}_{2}$ was as follows. PENTA-N ${ }_{3}(87.1 \mathrm{mg}$, $0.15 \mathrm{mmol}, 0.6 \mathrm{mmol}-\mathrm{N}_{3}$ group), $\mathrm{HC} \equiv \mathrm{C}-\mathrm{PCL}(0.687 \mathrm{~g}, 0.3$ $\mathrm{mmol}), \mathrm{HC} \equiv \mathrm{C}-\mathrm{PLLA}(0.84 \mathrm{~g}, 0.3 \mathrm{mmol})$ and DMF $(30 \mathrm{~mL})$, were added into a round bottom flask. After dissolution was complete, the solution was sparged with nitrogen for $15 \mathrm{~min}$, then $\mathrm{CuBr}$ (86.1 mg, $0.6 \mathrm{mmol}$ ) and PMDETA (104 mg, 0.6 mmol) were added. The mixture in the flask was degassed by three freeze-vacuum-thaw cycles. Then, nitrogen gas was 
introduced into the flask and the flask was immersed into an oil bath at $60{ }^{\circ} \mathrm{C}$ for $48 \mathrm{~h}$. After the reaction was carried out for prescribed time, the flask was rapidly cooled to room temperature by ice water. The Merrifield's resin-azide $(0.2 \mathrm{~g}, 0.32 \mathrm{mmol}$ $-\mathrm{N}_{3}$ group) was added into the flask. The mixture in the flask was degassed by three freeze-vacuum-thaw cycles. Then, nitrogen gas was introduced into the flask and the flask was immersed into an oil bath at $60{ }^{\circ} \mathrm{C}$ for $24 \mathrm{~h}$. The polymer solution was passed through a short column of neutral alumina to remove the metal salt and Merrifield's resin-azide. After the polymer solution was concentrated, it was precipitated in methyl alcohol. The product after suction filtration was dried in vacuum at room temperature to constant weight. The conversion rate is calculated by the weighing method.

$M_{\mathrm{n}, \mathrm{NMR}}=10520, M_{\mathrm{n}, \mathrm{GPC}}=7130, M_{\mathrm{w}} / M_{\mathrm{n}}=1.22 .{ }^{1} \mathrm{H} \mathrm{NMR}$ $\left(\mathrm{CDCl}_{3}, \delta, \mathrm{ppm}\right): 7.77\left(1 \mathrm{H}, \mathrm{CH}\right.$ in triazole ring), $5.23\left(2 \mathrm{H},-\mathrm{CH}_{2} \mathrm{O}\right.$ conjoint to the triazole ring), $5.18(1 \mathrm{H}, \mathrm{CHO}$ in PLLA), $4.35(1 \mathrm{H}$, terminal $\mathrm{CHO}$ in PLLA), $4.20\left(2 \mathrm{H}, \mathrm{CH}_{2} \mathrm{O}\right.$ in PENTA initiator), $4.06\left(2 \mathrm{H}, \mathrm{CH}_{2} \mathrm{O}\right.$ in $\left.\mathrm{PCL}\right), 3.65$ (2H, terminal $\mathrm{CH}_{2} \mathrm{O}$ in $\left.\mathrm{PCL}\right), 2.31$ $\left(2 \mathrm{H}, \mathrm{COCH}_{2}\right.$ in $\left.\mathrm{PCL}\right), 1.95\left(6 \mathrm{H},-\mathrm{CH}_{3}\right.$ in the BiBB group), 1.64 (4H, $\mathrm{CH}_{2}$ in PCL), 1.58 (3H, $\mathrm{CH}_{3}$ in PLLA), $1.38\left(2 \mathrm{H}, \mathrm{CH}_{2}\right.$ in PCL). IR $\left(\mathrm{cm}^{-1}\right)$ : 3430-3560, 2997, 2943, 2865, 1756, 1729, 1453, 1385, 1360, 1265, 1210, 1180, 1127, 1083, 1042, 946, 920, 867, 832, 759, $741,698$.

\subsection{Characterization}

${ }^{1} \mathrm{H}$ nuclear magnetic resonance (NMR) spectra was determined on a Bruker DMX-500 NMR instrument using $\mathrm{CDCl}_{3}$ as solvent and tetramethylsilane (TMS) as inner standard. Fourier transform infrared (FT-IR) spectra was recorded on an AVATAR 360 ESP FT-IR instrument. The measurement of molecular weights and molecular weight distribution of the polymers was carried out on a Waters 150C gel permeation chromatograph (GPC). Polystyrene was used as a calibration standard. $\mathrm{CHCl}_{3}$ was used as the eluent at a flow rate of $1.0 \mathrm{~mL} \mathrm{~min}^{-1}$. Differential scanning calorimeter (DSC) was determined on Q100 from the United States TA company. The mass of the powder sample was 1 to $3 \mathrm{mg}$. The test conditions were: a heating rate of $10{ }^{\circ} \mathrm{C} \min ^{-1}$ and a test interval of $-20{ }^{\circ} \mathrm{C}$ to $190{ }^{\circ} \mathrm{C}$. Phase analysis of the sample was performed on a Rigaku D/max X-ray diffractometer (XRD) using a $\mathrm{Cu}$ target with an accelerating voltage of $40 \mathrm{kV}$, a current intensity of $150 \mathrm{~mA}$, a scanning range of $5^{\circ}$ to $50^{\circ}$ and a scanning speed of $4^{\circ} \mathrm{min}^{-1}$. The sample was ground powder or flat polymer film.

\section{Results and discussion}

\subsection{Synthesis of 2-azido pentaerythritol isobutyrate (PENTA-}

$\mathbf{N}_{3}$ )

PENTA- $\mathrm{N}_{3}$ was synthesized by a two-step reaction using a pentaerythritol as a raw material. The infrared spectrum is shown in Fig. 1. The FT-IR spectrum of PENTA (Fig. 1(a)) has a strong hydroxyl absorption peak in the range of $3000-3500 \mathrm{~cm}^{-1}$, but the absorption peak disappeared in the FT-IR spectrum of PENTA-Br (Fig. 1(b)), indicating that the hydroxyl group has been completely substituted. In addition, a strong absorption

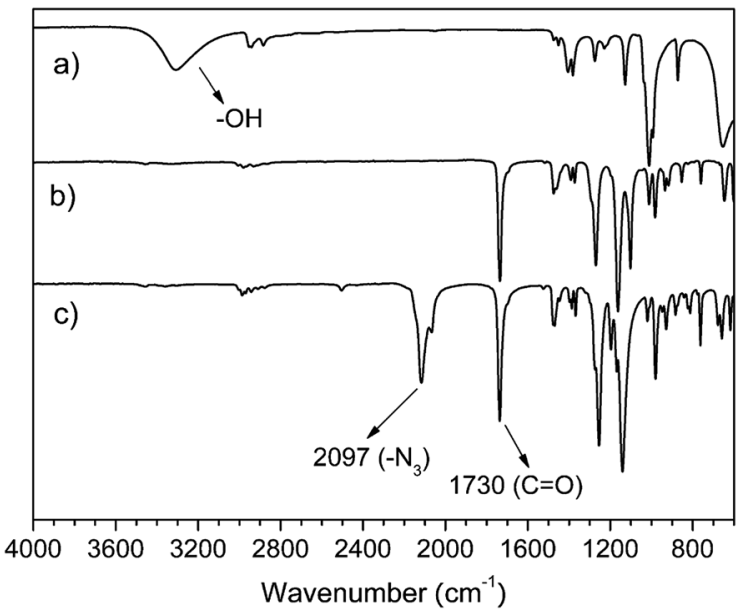

Fig. 1 FT-IR spectra of (a) PENTA, (b) PENTA-Br and (c) PENTA-N 3.

peak appears at $1730 \mathrm{~cm}^{-1}$ in Fig. 2(b), which is a characteristic peak of the carbonyl group $(\mathrm{C}=\mathrm{O})$. It can be assigned to the carbonyl group on 2-bromoisobutyryl, demonstrating that the hydroxyl group of pentaerythritol is substituted by 2-bromoisobutyryl. The difference between Fig. 1(c) and 1(b) is that an intense absorption peak appears at $2097 \mathrm{~cm}^{-1}$ in Fig. 1(c), which is a characteristic peak of the azide group $\left(-\mathrm{N}_{3}\right)$. It is demonstrated that the bromine atom on PENTA-Br is azided effectively.

For confirmation of the polymer structure, the ${ }^{1} \mathrm{H}$ NMR spectra were measured and a typical spectrum is shown in Fig. 2. There are two distinct signal peaks in the ${ }^{1} \mathrm{H}$ NMR spectrum of PENTA-Br (Fig. 2(a)). The peak at $\delta=4.33 \mathrm{ppm}$ is attributed to protons on the methylene group $-\mathrm{CH}_{2} \mathrm{O}-$ in the

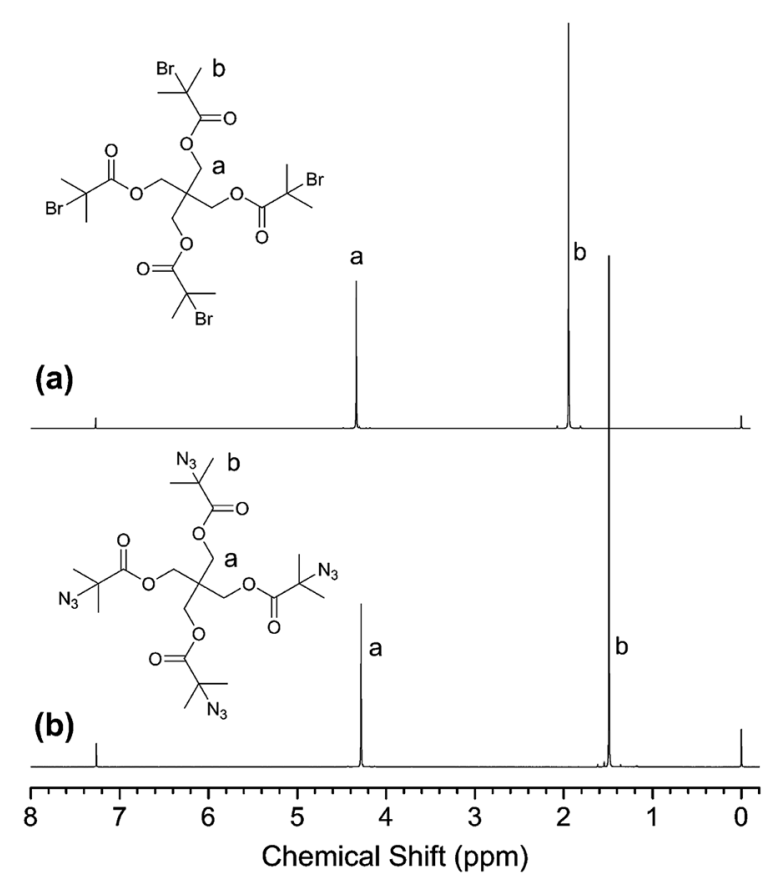

Fig. $2{ }^{1} \mathrm{H}-\mathrm{NMR}$ spectra of (a) PENTA-Br and (b) PENTA-N 3 . 
pentaerythritol structure (a), and the peak at $\delta=1.94 \mathrm{ppm}$ is assigned to protons on methyl- $\mathrm{CH}_{3}$ in 2-bromoisobutyryl (b). Also, the ratio of the integrated area of the two peaks $a: b$ is approximately $1: 3$, which indicate that the hydroxyl group on pentaerythritol is completely replaced by 2-bromoisobutyryl. Compared with Fig. 2(a), the peaks at $\delta=4.33$ and $1.94 \mathrm{ppm}$ have completely disappeared in Fig. 2(b). Instead, two distinct new peaks occur at $\delta=4.28$ and $1.49 \mathrm{ppm}$, which are assigned to protons on methylene $-\mathrm{CH}_{2} \mathrm{O}$ - in the pentaerythritol structure (a) and protons on methyl- $\mathrm{CH}_{3}$ in 2-azidoisobutyryl (b). It is demonstrated the bromine atom on the pentaerythritol ester is replaced by an azide group. Similarly, the ratio of the integrated areas of two peaks $a: b$ is approximately $1: 3$, indicating that the bromine atom is completely replaced by azide groups. Thus, a multifunctional small molecule initiator PENTA-N $_{3}$ with a well-defined structure and highly purity was synthesized successfully.

\subsection{Synthesis of the alkynyl terminated prepolymers}

$\mathrm{HC} \equiv \mathrm{C}$-PCL was prepared by the ROP of $\varepsilon$-caprolactone in $110{ }^{\circ} \mathrm{C}$ with propargyl alcohol as a small molecule initiator. $\mathrm{HC} \equiv \mathrm{C}$-PLLA was prepared by the ROP of L-lactide in $115^{\circ} \mathrm{C}$ with propargyl alcohol as a small molecule initiator. Further, $\mathrm{HC} \equiv \mathrm{C}-$ PCL- $b$-PLLA was prepared by the ROP of L-lactide in $115^{\circ} \mathrm{C}$ with $\mathrm{HC} \equiv \mathrm{C}-\mathrm{PCL}$ as macroinitiator. The FT-IR spectrums of $\mathrm{HC} \equiv \mathrm{C}$ PCL, HC $\equiv \mathrm{C}$-PLLA and HC $\equiv \mathrm{C}$-PCL- $b$-PLLA were shown in Fig. 3. The strong absorption peak at $1729 \mathrm{~cm}^{-1}$ in Fig. 3(a) and (c) could be attributed to the stretching vibration peak of carbonyl $(\mathrm{C}=\mathrm{O})$ in the PCL molecular chain. The strong absorption peak at $1756 \mathrm{~cm}^{-1}$ in Fig. 3(b) and (c) could be attributed to the stretching vibration peak of carbonyl $(\mathrm{C}=\mathrm{O})$ in the PLLA molecular chain. The absorption peak at $3250 \mathrm{~cm}^{-1}$ in Fig. 3(a) and (b) belongs to the characteristic peak of alkyne, which can prove that the synthesized PCL and PLLA contains alkyne groups. In addition, the absorption peak attributed to the alkynyl group is difficult to distinguish in Fig. 3(c), probably because the signal is too weak to be masked.

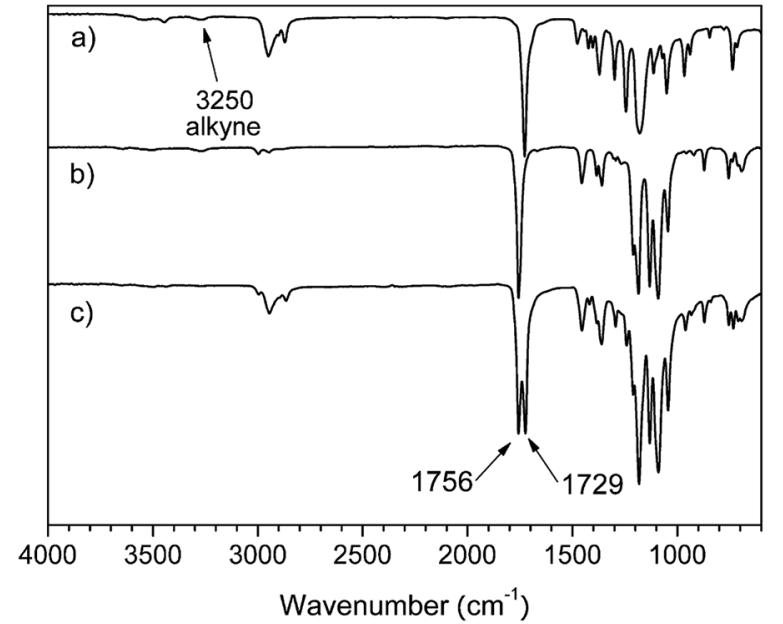

Fig. $3 \mathrm{FT}-\mathrm{IR}$ spectra of (a) $\mathrm{HC} \equiv \mathrm{C}-\mathrm{PCL}$, (b) $\mathrm{HC} \equiv \mathrm{C}-\mathrm{PLLA}$ and (c) $\mathrm{HC} \equiv \mathrm{C}-\mathrm{PCL}-b-\mathrm{PLLA}$.
The chemical structure of polymer arms with end acetylene were further characterized by ${ }^{1} \mathrm{H}$ NMR, as shown in Fig. 4. The signal peaks a to d in Fig. 4(a) all belong to the PCL chain. The peak at $\delta=4.06 \mathrm{ppm}$ is assigned to the hydrogen on the $-\mathrm{CH}_{2} \mathrm{O}-$ methylene group in the repeating unit on the PCL chain (d). The small signal peak at $\delta=3.65 \mathrm{ppm}$ is attributed to hydrogen on the $-\mathrm{CH}_{2} \mathrm{O}$-methylene group in the last repeat unit of the PCL chain $\left(\mathrm{d}^{\prime}\right)$, which is caused by chemical shifts of the terminal hydroxyl group. Two strong signal peaks appear at $\delta=5.17 \mathrm{ppm}$ (e) and $\delta=1.58$ ppm (f) in Fig. 4(b) can be attributed to the proton of $-\mathrm{CH}-\mathrm{CH}_{3}$ (e) and $-\mathrm{CH}_{3}$ on repeat units in the PLLA molecule chain. And the signal peak at $4.37 \mathrm{ppm}\left(\mathrm{e}^{\prime}\right)$ belongs to proton on the $-\mathrm{CH}-\mathrm{CH}_{3}$ in the PLLA molecule chain. In addition, it can be seen that two signal peaks at almost $\delta=2.50$ and $4.72 \mathrm{ppm}$, which belong to protons of the alkynyl group and the methylene group attached to the alkynyl group, respectively. The integration ratio of $\mathrm{h}: \mathrm{g}: \mathrm{d}^{\prime}$ (Fig. 4(a)), $\mathrm{e}^{\prime}: \mathrm{h}: \mathrm{g}$ (Fig. 4(b)) and $\mathrm{h}: \mathrm{g}: \mathrm{e}^{\prime}$ (Fig. 4(c)) are approximately $1: 2: 2$, indicating that each molecule chain has one terminal alkyne group and one hydroxyl group terminal group.

In addition, the molecular weight of $\mathrm{HC} \equiv \mathrm{C}-\mathrm{PCL}, \mathrm{HC} \equiv \mathrm{C}$ PLLA and HC $\equiv$ C-PCL- $b$-PLLA can also be calculated by the

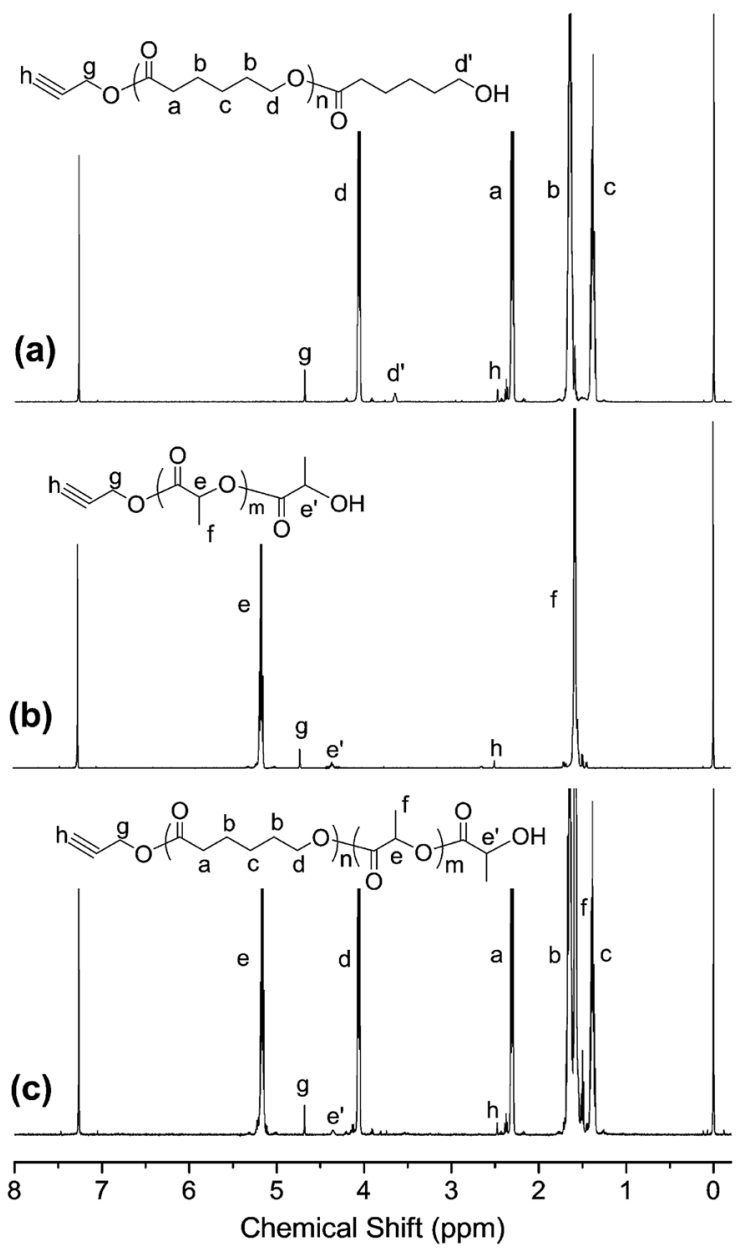

Fig. $4{ }^{1} \mathrm{H}-\mathrm{NMR}$ spectra of (a) $\mathrm{HC} \equiv \mathrm{C}-\mathrm{PCL}$, (b) $\mathrm{HC} \equiv \mathrm{C}-\mathrm{PLLA}$ and (c) $\mathrm{HC} \equiv \mathrm{C}-\mathrm{PCL}-b-\mathrm{PLLA}$. 
integrated areas $I_{\mathrm{e}}, I_{\mathrm{g}}$ and $I_{\mathrm{d}}$ of the three signal peaks at the 5.17, 4.68 and 4.06 ppm displacements according to eqn (1) to (3).

$$
\begin{aligned}
& M_{\mathrm{n}, \mathrm{NMR}}[\mathrm{HC} \equiv \mathrm{C}-\mathrm{PCL}]=I_{\mathrm{d}} / I_{\mathrm{g}} \times 114+56 \\
& M_{\mathrm{n}, \mathrm{NMR}}[\mathrm{HC} \equiv \mathrm{C}-\mathrm{PLLA}]=I_{\mathrm{e}} / I_{\mathrm{g}} \times 144+56 \\
& M_{\mathrm{n}, \mathrm{NMR}}[\mathrm{HC} \equiv \mathrm{C}-\mathrm{PCL}-b-\mathrm{PLLA}]=I_{\mathrm{d}} / I_{\mathrm{g}} \times 114+I_{\mathrm{e}} / I_{\mathrm{g}} \\
& \times 144+56
\end{aligned}
$$

here 114, 144 and 56 are the molecular weight of the caprolactone monomer, lactide monomer and terminal alkynyl group. The calculated results are listed in Table 1 . The agreement of $M_{\mathrm{n}, \mathrm{NMR}}, M_{\mathrm{n}, \mathrm{th}}$ and $M_{\mathrm{n}, \mathrm{GPC}}$ proves the formation of $\mathrm{HC} \equiv \mathrm{C}-\mathrm{PCL}-b$-PLLA block copolymers. $M_{\mathrm{n}, \mathrm{NMR}}$ is consistent with $M_{\mathrm{n}, \mathrm{th}}$ and $M_{\mathrm{n}, \mathrm{GPC}}$. The molecular weight distribution measured by GPC are all narrowly distributed.

\subsection{Synthesis of star homopolymers 4SPCL and 4SPLLA}

The click reaction was performed at $60{ }^{\circ} \mathrm{C}$ with $\mathrm{CuBr} / \mathrm{PMDETA}$ as catalyst. To ensure high conversion of PENTA- $\mathrm{N}_{3}$, a little superfluous $\mathrm{HC} \equiv \mathrm{C}-\mathrm{PCL}$ and $\mathrm{HC} \equiv \mathrm{C}$-PLLA were needed, respectively. After the click reaction, they were removed by treated with Merrifield's resin-azide. The resultant star homopolymers (4sPCL and 4sPLLA) was characterized by FT-IR, $1 \mathrm{H}$ NMR and GPC. The FT-IR spectrums of 4sPCL and 4sPLLA were shown in Fig. 5(a) and (b). Compared with Fig. 3(a) and (b), the characteristic peak of alkyne at $3250 \mathrm{~cm}^{-1}$ disappears, and the characteristic peak of azide group at $2097 \mathrm{~cm}^{-1}$ can't be found anymore. It is demonstrated that the click reaction consumes the alkyne and azide groups.

The chemical structure of star homopolymers were further characterized by ${ }^{1} \mathrm{H}$ NMR, as shown in Fig. 6. Compared with Fig. 4, two signal peaks at $\delta=2.47$ and $4.68 \mathrm{ppm}$, which belong to protons of the alkynyl group and the methylene group attached to the alkynyl group, have disappeared completely. Instead, the peak at $\delta=5.22 \mathrm{ppm}(\mathrm{g})$ and $7.78 \mathrm{ppm}(\mathrm{h})$ appear, which are assigned to protons of the 1,2,3-triazole ring paramethylene $(\mathrm{g})$ and the methylene proton (h). In addition, compared with Fig. 2(b), the signal peaks at $\delta=4.28$ and $1.49 \mathrm{ppm}$ that belong to the methylene protons and methyl

Table 1 Molecular weight and conversion rate data for polymer arms with end acetylene

\begin{tabular}{llllll}
\hline Samples & $M_{\mathrm{n}, \mathrm{th}}{ }^{a}$ & $M_{\mathrm{n}, \mathrm{NMR}}{ }^{b}$ & $M_{\mathrm{n}, \mathrm{GPC}}{ }^{c}$ & $M_{\mathrm{w}} / M_{\mathrm{n}}{ }^{c}$ & Conv $^{d}(\%)$ \\
\hline HC $\equiv$ C-PCL & 2300 & 2290 & 2350 & 1.17 & 98.3 \\
HC $\equiv$ C-PLLA & 2810 & 2800 & 2950 & 1.21 & 95.4 \\
HC $\equiv$ C-PCL-b-PLLA & 5080 & 5100 & 5160 & 1.20 & 96.9
\end{tabular}

${ }^{a} M_{\mathrm{n}, \mathrm{th}}$ denotes the theoretical number-average molecular weight of polymers. $M_{\mathrm{n}, \mathrm{th}}$ of $\mathrm{HC} \equiv \mathrm{C}-\mathrm{PCL}, \mathrm{HC} \equiv \mathrm{C}-\mathrm{PLLA}$, and HC$\equiv \mathrm{C}-\mathrm{PCL}-b$-PLLA can be calculated according to the equation: $M_{\mathrm{n}, \mathrm{th}}=$ [monomer]/ [initiator] $\times M_{\text {monomer }} \times$ Conv (\%) $+M_{\text {initiator }}$, where [monomer] and [initiator] are initial concentrations of monomers and initiators, $M_{\text {initiator }}$ is the number-average molecular weight of initiator. ${ }^{b}$ Determined by ${ }^{1} \mathrm{H}$ NMR spectroscopy of polymers. ${ }^{c}$ Determined by GPC analysis with polystyrene standards. $\mathrm{CHCl}_{3}$ was used as eluent.

${ }^{d}$ Conversion of monomer obtained from gravimetry.

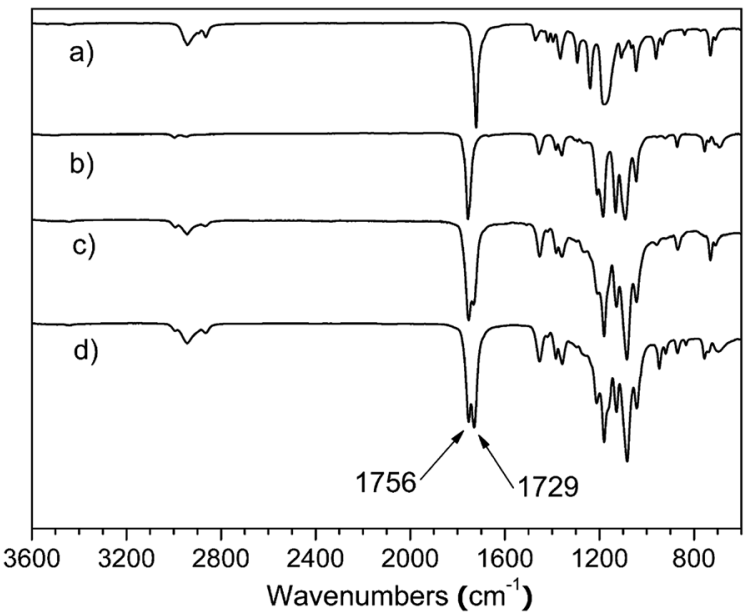

Fig. 5 FT-IR spectra of star-shaped copolymers: (a) 4sPCL, (b) 4sPLLA, (c) $4 \mathrm{sPCL}-b-\mathrm{PLLA}$, (d) $\mathrm{PCL}_{2} \mathrm{PLLA}_{2}$.

protons on the initiator central molecule also disappear completely, and are replaced by two new signal peaks at $\delta=4.20$ and 1.95 ppm in Fig. 6. It is illustrated that the alkyne and azide groups are consumed completely by the click reaction and 1,2,3triazole ring groups are formed.

Combining the changes of the GPC curve before and after the click reaction (Fig. 7), the GPC curves of the raw materials $\mathrm{HC} \equiv \mathrm{C}-\mathrm{PCL}$ and $\mathrm{HC} \equiv \mathrm{C}-\mathrm{PLLA}$ are both single-peak and are on the lower molecular weight side. The GPC curve of the clickresponse product is also single-peak and has a significant shift to the high molecular weight direction. It is showed that

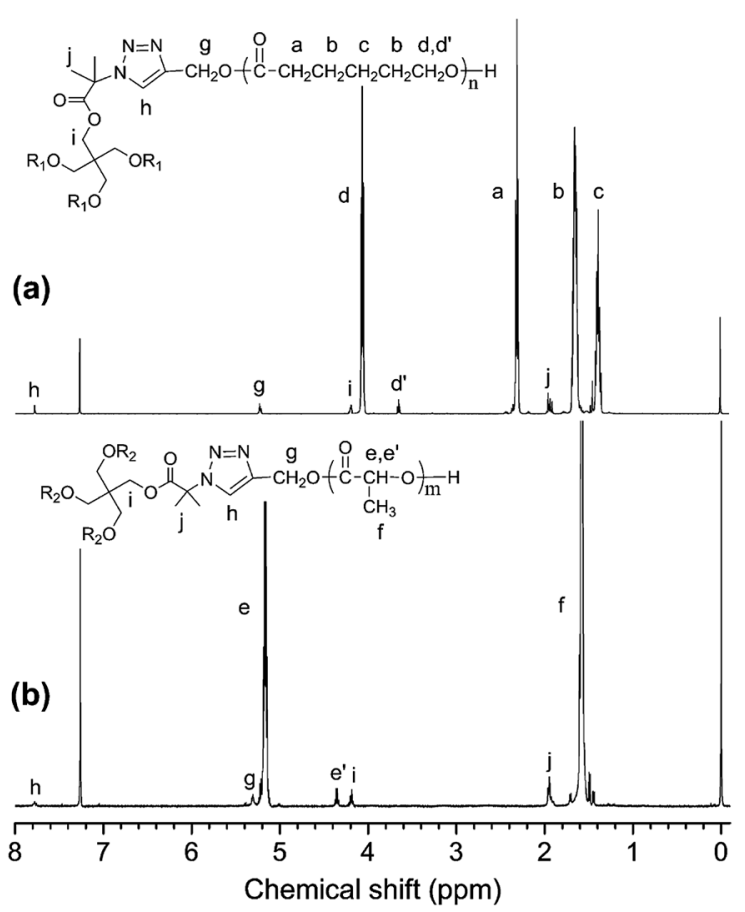

Fig. $6{ }^{1} \mathrm{H}-\mathrm{NMR}$ spectra of star-shaped copolymers: (a) $4 \mathrm{sPCL}$, (b) 4sPLLA. 


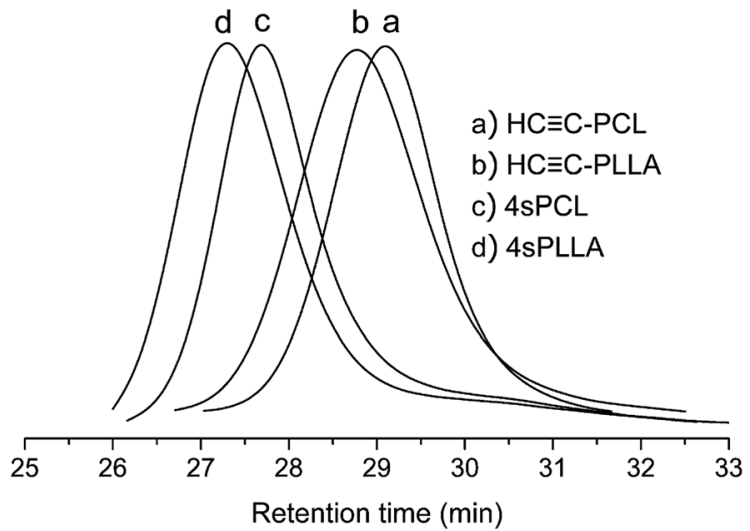

Fig. 7 GPC traces of (a) $\mathrm{HC} \equiv \mathrm{C}-\mathrm{PCL}$, (b) $\mathrm{HC} \equiv \mathrm{C}-\mathrm{PLLA}$, (c) $4 \mathrm{sPCL}$ and (d) 4 SPLLA.

the formation of a larger molecular weight star homopolymers (4sPCL and 4sPLLA). At the same time, we also find that there are trace unreacted linear polymers. The advantage of this synthetic method is simple and quick, but it is also difficult to avoid the presence of trace unreacted liner polymers.

In addition, the molecular weight of star-shaped copolymers can also be calculated by the integrated areas $I_{\mathrm{h}}, I_{\mathrm{e}}$ and $I_{\mathrm{d}}$ of the three signal peaks at the $7.78 \mathrm{ppm}, 5.16 \mathrm{ppm}$ and $4.07 \mathrm{ppm}$ displacements according to eqn (4) and (5).

$$
\begin{gathered}
M_{\mathrm{n}, \mathrm{NMR}}[4 \mathrm{sPCL}]=\left(I_{\mathrm{d}} / 2 I_{\mathrm{h}} \times 114+56\right) \times 4+581 \\
M_{\mathrm{n}, \mathrm{NMR}}[4 \mathrm{sPLLA}]=\left(I_{\mathrm{e}} / 2 I_{\mathrm{h}} \times 144+56\right) \times 4+581
\end{gathered}
$$

here 114, 144 and 56 and 581 are the molecular weight of the caprolactone monomer, lactide monomer, terminal alkynyl group and PENTA- $\mathrm{N}_{3}$. The calculated results are listed in Table 2. The $M_{\mathrm{n}, \mathrm{NMR}}$ and the $M_{\mathrm{n}, \mathrm{th}}$ are in agreement, but they are also significantly different from the $M_{\mathrm{n}, \mathrm{GPC}}$. The $M_{\mathrm{n}, \mathrm{GPC}}$ is significantly lower than $M_{\mathrm{n}, \mathrm{NMR}}$ and $M_{\mathrm{n}, \mathrm{th}}$, which is due to the hydrodynamic volume difference between the star polymer and the linear polymer. The most important feature of star polymers is that they have more segment density than linear polymers of the same molecular weight, which makes star polymers

Table 2 Molecular weight and conversion rate data for star-shaped copolymers

\begin{tabular}{lrrrr}
\hline Sample & $M_{\mathrm{n}, \mathrm{th}}{ }^{a}$ & $M_{\mathrm{n}, \mathrm{NMR}}{ }^{b}$ & $M_{\mathrm{n}, \mathrm{GPC}}{ }^{c}$ & $M_{\mathrm{w}} / M_{\mathrm{n}}{ }^{c}$ \\
\hline 4sPCL & 9780 & 9910 & 6320 & 1.15 \\
4sPLLA & 11820 & 12500 & 8750 & 1.21 \\
4sPCL- $b$-PLLA & 20900 & 19030 & 12600 & 1.18 \\
PCL $_{2}$ PLLA $_{2}$ & 10800 & 10520 & 7130 & 1.22
\end{tabular}

${ }^{a} M_{\mathrm{n}, \text { th }}$ denotes the theoretical number-average molecular weight of polymers: $\quad M_{\mathrm{n}, \mathrm{th}}=M_{\mathrm{n}, \mathrm{th}}[$ prepolymer $] \times 4+581$, where $M_{\mathrm{n}, \mathrm{th}}\left[\right.$ prepolymer] is $M_{\mathrm{n}, \mathrm{th}}$ of $\mathrm{HC} \equiv \mathrm{C}-\mathrm{PCL}, \mathrm{HC} \equiv \mathrm{C}-\mathrm{PLLA}$, or $\mathrm{HC} \equiv \mathrm{C}$ PCL- $b$-PLLA, 581 is the molecular weight of PENTA-N $\mathrm{N}_{3}$; $M_{\mathrm{n}, \mathrm{th}}\left[\mathrm{PCL}_{2} \mathrm{PLLA}_{2}\right]=\left(M_{\mathrm{n}, \mathrm{th}}[\mathrm{HC} \equiv \mathrm{C}-\mathrm{PCL}]+M_{\mathrm{n}, \mathrm{th}}[\mathrm{HC} \equiv \mathrm{C}-\mathrm{PLLA}]\right) \times 2+$ 581. ${ }^{b}$ Determined by ${ }^{1} \mathrm{H}$ NMR spectroscopy of polymers. ${ }^{c}$ Determined by GPC analysis with polystyrene standards. $\mathrm{CHCl}_{3}$ was used as eluent. generally have smaller hydrodynamic volumes. In a size exclusion chromatography device, the smaller hydrodynamic volume allows the polymer to have a larger outflow volume for a specific time. This means that when linear polymer standards are used in GPC testing, the apparent molecular weight of highly branched polymers such as star polymers is often far below their actual molecular weight. ${ }^{\mathbf{4 3}}$ However, it can be referred to as a result that the $M_{\mathrm{n}, \mathrm{GPC}}$ is larger than that of the linear raw material polymer.

\subsection{Synthesis of the star-block copolymer 4sPCL-b-PLLA}

The click reaction was performed at $60{ }^{\circ} \mathrm{C}$ with $\mathrm{CuBr} / \mathrm{PMDETA}$ as catalyst. To ensure high conversion of PENTA- $\mathrm{N}_{3}$, a little superfluous $\mathrm{HC} \equiv \mathrm{C}$-PCL- $b$-PLLA was needed. After the click reaction, they were removed by treated with Merrifield's resinazide. The resultant star-block copolymer 4sPCL- $b$-PLLA was characterized by FT-IR, ${ }^{1} \mathrm{H}$ NMR and GPC. The FT-IR spectrums of star-shaped copolymer was shown in Fig. 5(c). There are two obvious absorption peaks from 1729 to $1756 \mathrm{~cm}^{-1}$, which belong to the stretching vibration peaks of hydroxyl $(\mathrm{C}=\mathrm{O})$ on PCL and PLLA chains respectively. The characteristic peak of alkyne at $3250 \mathrm{~cm}^{-1}$ and the characteristic peak of azide group at $2097 \mathrm{~cm}^{-1}$ disappear. It is also demonstrated that the click reaction consumes the alkyne and azide groups.

The chemical structure of star-block copolymer was further characterized by ${ }^{1} \mathrm{H}$ NMR, as shown in Fig. 8. Compared with Fig. 4(c), two signal peaks at $\delta=2.47$ and $4.68 \mathrm{ppm}$, which belong to protons of the alkynyl group and the methylene group attached to the alkynyl group, have disappeared completely. Instead, the peak at $\delta=5.22 \mathrm{ppm}(\mathrm{g})$ and $7.79 \mathrm{ppm}(\mathrm{h})$ appear, which are assigned to protons of the 1,2,3-triazole ring paramethylene $(\mathrm{g})$ and the methylene proton (h). In addition, compared with Fig. 2(b), the signal peaks at $\delta=4.28$ and $1.49 \mathrm{ppm}$ that belong to the methylene protons and methyl protons on the initiator central molecule also disappear completely, and are replaced by two new signal peaks at $\delta=4.21$ and 1.94 ppm in Fig. 6. It is illustrated that the alkyne and azide

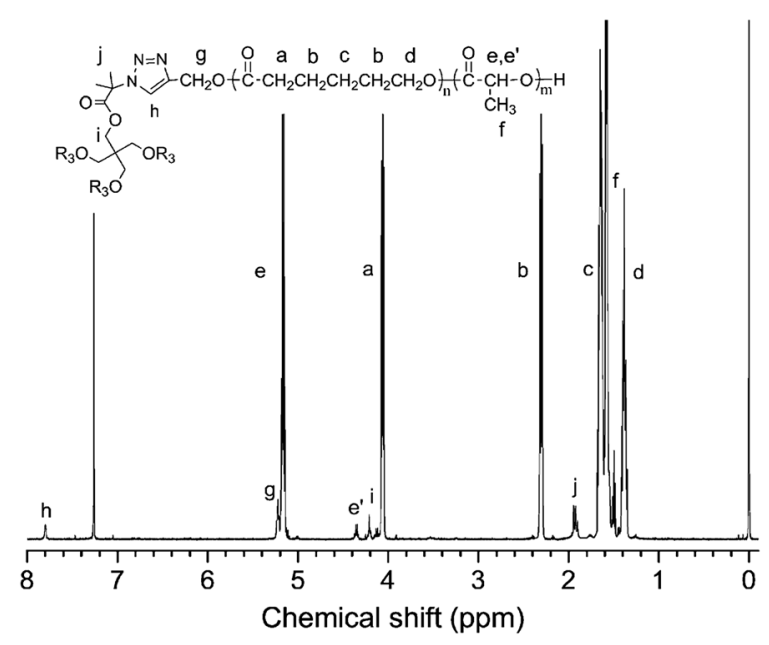

Fig. $8{ }^{1} \mathrm{H}$-NMR spectra of the star-block copolymer 4sPCL-b-PLLA. 


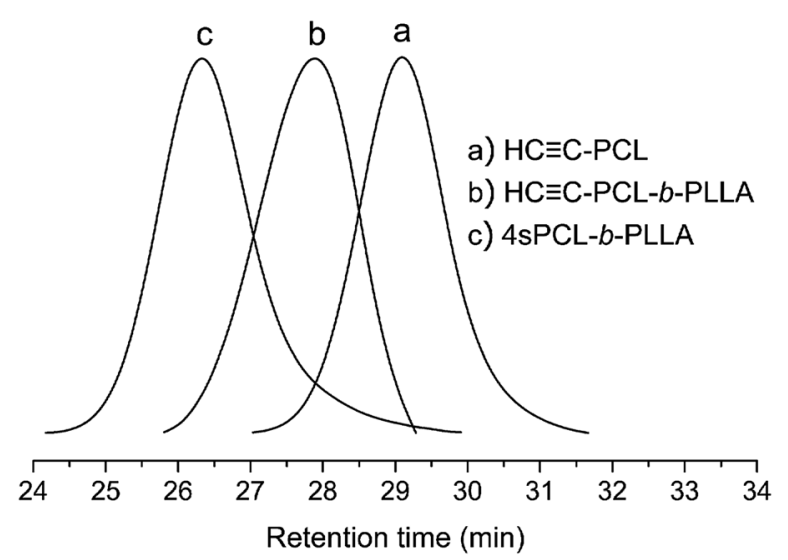

Fig. $9 \mathrm{GPC}$ traces of (a) $\mathrm{HC} \equiv \mathrm{C}-\mathrm{PCL}$, (b) $\mathrm{HC} \equiv \mathrm{C}-\mathrm{PLLA}$ and (c) $4 \mathrm{SPCL}-$ b-PLLA.

groups are consumed completely by the click reaction and 1,2,3triazole ring groups are formed.

Combining the changes of the GPC curve before and after the click reaction (Fig. 9), the GPC curves of the raw materials $\mathrm{HC} \equiv \mathrm{C}-\mathrm{PCL}$ is on the lower molecular weight side, but the block copolymer $\mathrm{HC} \equiv \mathrm{C}$-PCL- $b$-PLLA has a significant shift to the high molecular weight direction. $\mathrm{HC} \equiv \mathrm{C}-\mathrm{PCL}$ and $\mathrm{HC} \equiv \mathrm{C}-\mathrm{PCL}-b$ PLLA are both single-peak. It is illustrated that the ROP could be used to synthesize narrow-distributed block copolymer. In addition, the GPC curve of the click-response product 4sPCL- $b$ PLLA is also single-peak and has a significant shift to the high molecular weight direction. It is showed that the formation of a larger molecular weight star-block copolymer 4sPCL-b-PLLA. However, it is also difficult to avoid the presence of trace unreacted liner polymers, as shown in Fig. 9.

The molecular weight of the star-block copolymer can also be calculated by the integrated areas $I_{\mathrm{h}}, I_{\mathrm{e}}$ and $I_{\mathrm{d}}$ of the three signal peaks at the $7.79 \mathrm{ppm}, 5.18 \mathrm{ppm}$ and $4.06 \mathrm{ppm}$ displacements according to eqn (6).

$$
\begin{aligned}
M_{\mathrm{n}, \mathrm{NMR}}[4 \mathrm{sPCL}-b-\mathrm{PLLA}]= & \left(I_{\mathrm{d}} / 2 I_{\mathrm{h}} \times 114+I_{\mathrm{e}} / 2 I_{\mathrm{h}} \times 144+56\right) \\
& \times 4+581
\end{aligned}
$$

here 114, 144, 56 and 581 are the molecular weight of the caprolactone monomer, lactide monomer, terminal alkynyl group and PENTA-N ${ }_{3}$. The calculated results are listed in Table 2. The $M_{\mathrm{n}, \mathrm{NMR}}$ and the $M_{\mathrm{n} \text {,th }}$ are in agreement, but they are also significantly different from the $M_{\mathrm{n}, \mathrm{GPC}}$. The $M_{\mathrm{n}, \mathrm{GPC}}$ is significantly lower than $M_{\mathrm{n}, \mathrm{NMR}}$ and $M_{\mathrm{n} \text {,th }}$, which is also due to the hydrodynamic volume difference between the star polymer and the linear polymer.

\subsection{Synthesis of the miktoarm star-shaped copolymer $\mathbf{P C L}_{2}$ PLLA $_{2}$}

The click reaction was performed at $60{ }^{\circ} \mathrm{C}$ with $\mathrm{CuBr} / \mathrm{PMDETA}$ as catalyst. To ensure that the number of the two arms is equal, a completely equal amount of $\mathrm{HC} \equiv \mathrm{C}-\mathrm{PCL}$ and $\mathrm{HC} \equiv \mathrm{C}-$ PLLA is added to the reaction, and there is basically no excess. After the click reaction, Merrifield's resin-azide is also

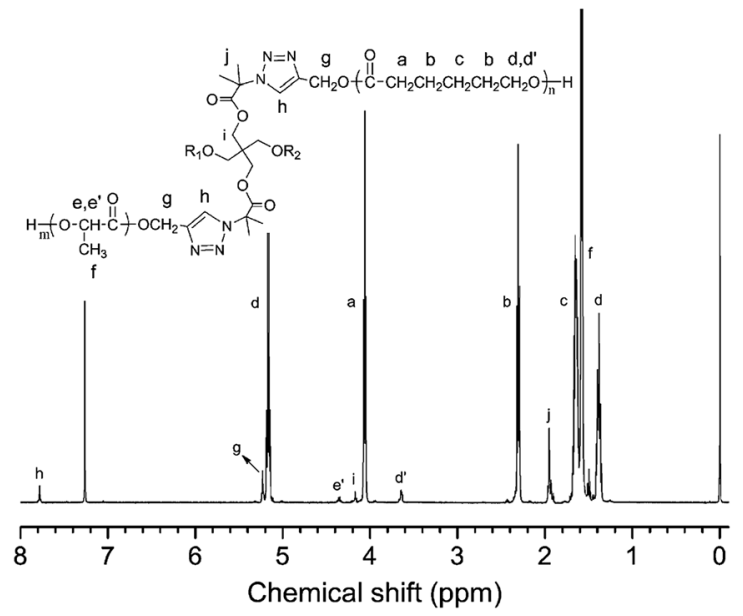

Fig. $10{ }^{1} \mathrm{H}$-NMR spectra of the miktoarm star copolymer $\mathrm{PCL}_{2} \mathrm{PLLA}_{2}$.

used to remove the unreacted end-acetylene. The resultant miktoarm star-shaped copolymer $\mathrm{PCL}_{2} \mathrm{PLLA}_{2}$ was characterized by FT-IR, ${ }^{1} \mathrm{H}$ NMR and GPC. The FT-IR spectrums of miktoarm star-shaped copolymer was shown in Fig. 5(d). There are two obvious absorption peaks from 1729 to $1756 \mathrm{~cm}^{-1}$, which belong to the stretching vibration peaks of hydroxyl $(\mathrm{C}=\mathrm{O})$ on PCL and PLLA chains respectively. The characteristic peak of alkyne at $3250 \mathrm{~cm}^{-1}$ and the characteristic peak of azide group at $2097 \mathrm{~cm}^{-1}$ disappear. It is also demonstrated that the click reaction consumes the alkyne and azide groups.

The chemical structure of star-shaped copolymers were further characterized by ${ }^{1} \mathrm{H}$ NMR, as shown in Fig. 10 . Compared with Fig. 4(a) and (b), two signal peaks at $\delta=2.47$ and $4.68 \mathrm{ppm}$, which belong to protons of the alkynyl group and the methylene group attached to the alkynyl group, have disappeared completely. Instead, the peak at $\delta=5.23$ and $7.77 \mathrm{ppm}$ appear, which are assigned to protons of the 1,2,3triazole ring paramethylene $(\mathrm{g})$ and the methylene proton (h). In addition, compared with Fig. 2(b), the signal peaks at $\delta=4.28$ and $1.49 \mathrm{ppm}$ that belong to the methylene protons and methyl protons on the initiator central molecule also disappear completely, and are replaced by two new signal peaks at $\delta=4.20$ and $1.95 \mathrm{ppm}$ in Fig. 6. It is illustrated that the alkyne and azide groups are consumed completely by the click reaction and 1,2,3triazole ring groups are formed.

Combining the changes of the GPC curve before and after the click reaction (Fig. 11), the GPC curves of the raw materials $\mathrm{HC} \equiv \mathrm{C}-\mathrm{PCL}$ and $\mathrm{HC} \equiv \mathrm{C}-\mathrm{PLLA}$ and the miktoarm star-shaped copolymer $\mathrm{PCL}_{2} \mathrm{PLLA}_{2}$ are all single-peak and are on the lower molecular weight side. The GPC curve of the click-response product is also single-peak and has a significant shift to the high molecular weight direction. It is showed that the formation of a larger molecular weight miktoarm star-shaped copolymer $\mathrm{PCL}_{2} \mathrm{PLLA}_{2}$. Although there is a slightly trailing on the side of low molecular weight in Fig. 11, it has been verified from the ${ }^{1} \mathrm{H}$ NMR results and molecular weight that the synthesis is basically successful. At the same time, we also find that there are trace unreacted linear polymers. From the point of the reaction 


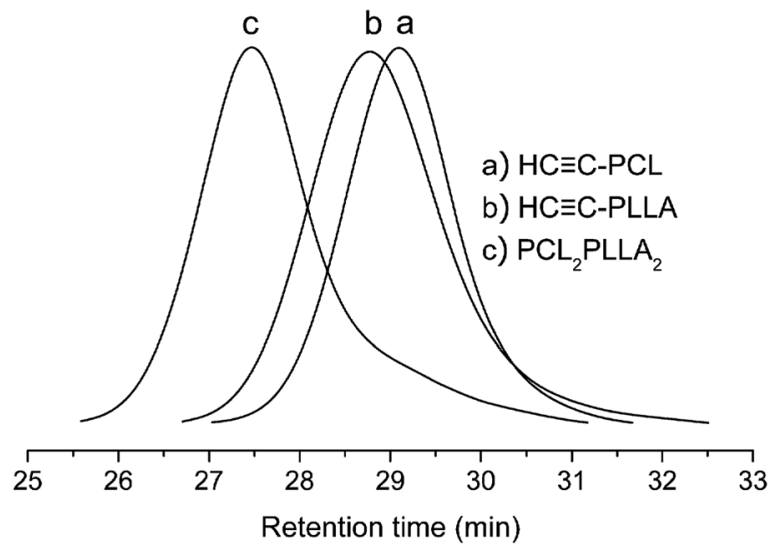

Fig. $11 \mathrm{GPC}$ traces of (a) $\mathrm{HC} \equiv \mathrm{C}-\mathrm{PCL}$, (b) $\mathrm{HC} \equiv \mathrm{C}-\mathrm{PLLA}$ and (c) $\mathrm{PCL}_{2} \mathrm{PLLA}_{2}$.

probability, $\mathrm{PLLA}_{2} \mathrm{PCL}_{2}$ should be the main product, but there are also trace by-products such as 4 sPLLA, 4sPCL, PLLA 3 PCL, PLLAPCL $_{3}$ and so on. The advantage of this synthetic method is simple and quick, but there are still drawbacks of trace unreacted liner polymers and trace by-products.

The molecular weight of the miktoarm star-shaped copolymer can also be calculated by the integrated areas $I_{\mathrm{h}}, I_{\mathrm{e}}$ and $I_{\mathrm{d}}$ of the three signal peaks at the $7.77 \mathrm{ppm}, 5.18 \mathrm{ppm}$ and $4.06 \mathrm{ppm}$ displacements according to eqn (7).

$$
\begin{aligned}
M_{\mathrm{n}, \mathrm{NMR}}\left[\mathrm{PCL}_{2} \mathrm{PLLA}_{2}\right]= & \left(I_{\mathrm{d}} / 2 I_{\mathrm{h}} \times 114+I_{\mathrm{e}} / 2 I_{\mathrm{h}} \times 144+56\right) \\
& \times 2+581
\end{aligned}
$$

here 114, 144, 56 and 581 are the molecular weight of the caprolactone monomer, lactide monomer, terminal alkynyl group and PENTA- $\mathrm{N}_{3}$. The calculated results are listed in Table 2. The $M_{\mathrm{n}, \mathrm{NMR}}$ and the $M_{\mathrm{n} \text {,th }}$ are in agreement, but they are also significantly different from the $M_{\mathrm{n}, \mathrm{GPC}}$. The $M_{\mathrm{n}, \mathrm{GPC}}$ is significantly lower than $M_{\mathrm{n}, \mathrm{NMR}}$ and $M_{\mathrm{n}, \mathrm{th}}$, which is also due to the hydrodynamic volume difference between the star polymer and the linear polymer.

\subsection{Comparison of melting and crystallization behavior of star-shaped copolymers}

In order to study the effect on the melting and crystallization behaviors of star-shaped copolymers, DSC was used to compare several synthetic star-shaped copolymers with linear polymers. The crystallization behavior of the polymer is studied by a constant-temperature cooling process after heating, and the melting behavior is studied by a secondary heating process, as shown in Fig. 12 and 13. Compared to linear polymers with the same molecular weight, the melting point and crystallization temperature of 4sPCL and 4sPLLA are lower. Because the melting and crystallization behavior of star-shaped copolymers reflect the characteristic of polymer chains on each arm. The shorter polymer chain on each arm causes a significant decrease in its melting point and crystallization temperature. In addition, the unique structure of star-shaped copolymers hinders the movement of segments, so the crystallization

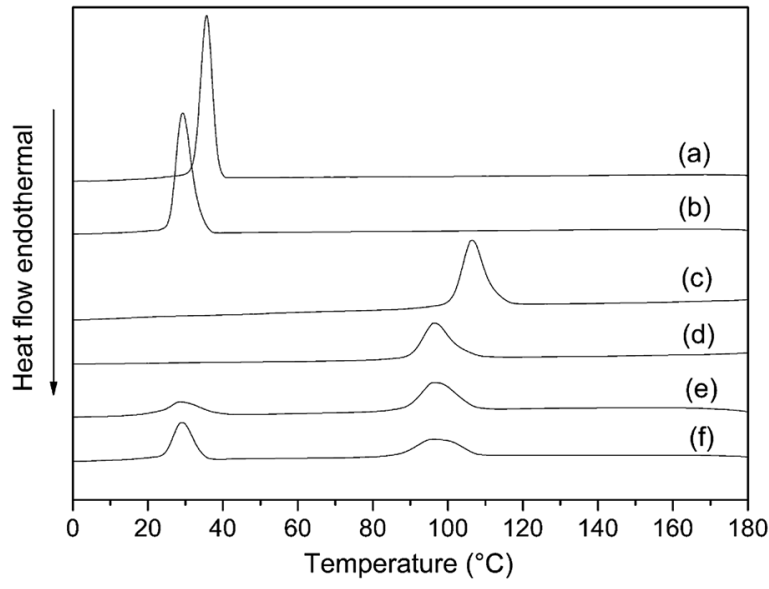

Fig. 12 DSC cooling curves of synthetic polymers: (a) linear PCL, (b) 4sPCL, (c) linear PLLA, (d) 4sPLLA, (e) 4sPCL-b-PLLA, (f) PCL ${ }_{2} \mathrm{PLLA}_{2}$.

properties of segments are affected. It can also be seen that 4sPCL and 4sPLLA have lower melting enthalpy and crystallinity than their linear polymers.

The star-block structure also affects the crystallization behavior of the polymer. As shown in Fig. 12(e), the crystallization peak of the PLLA segment in the star-block copolymer 4 sPCL- $b$-PLLA is obvious, while the crystallization peak of the PCL segment is very weak. It indicates that in the star-block structure, the segment of the outer block (PLLA) has better mobility and is advantageous for crystallization. But the mobility ability of the segment of the inner block (PCL) will be significantly limited and the ability to crystallize will deteriorate. It can also be seen in Fig. 13(e) that the melting peak of the inner block (PCL) is also very weak due to poor crystallization. Fig. 12(f) is the crystallization curve of the miktoarm starshaped copolymer $\mathrm{PCL}_{2} \mathrm{PLLA}_{2}$. It can be seen that there are both crystallization peaks for the PCL and PLLA segments. Compared with Fig. 12(e), the crystallization peak of PCL is more obvious because both PCL and PLLA chains are directly connected to the star core molecule. In the same environment,

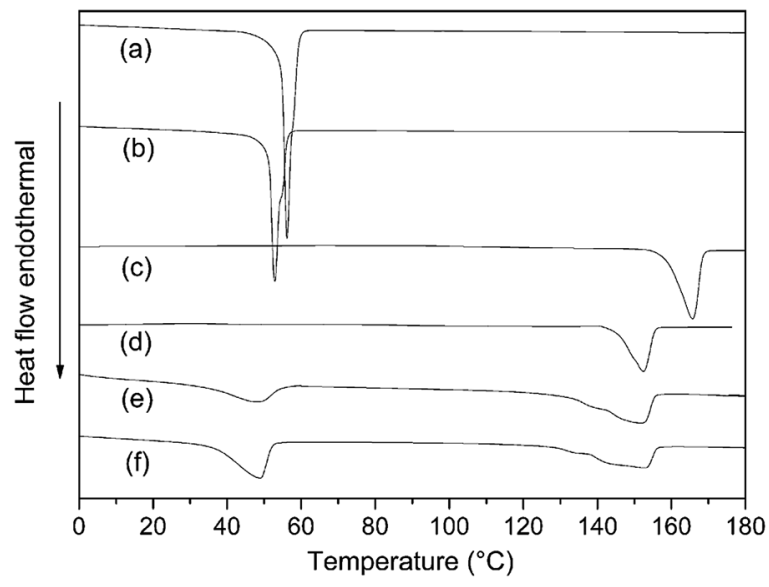

Fig. 13 Secondary heating DSC curve of synthetic polymers: (a) linear $\mathrm{PCL}$, (b) 4sPCL, (c) linear PLLA, (d) 4sPLLA, (e) 4sPCL-b-PLLA, (f) $\mathrm{PCL}_{2} \mathrm{PLLA}_{2}$. 


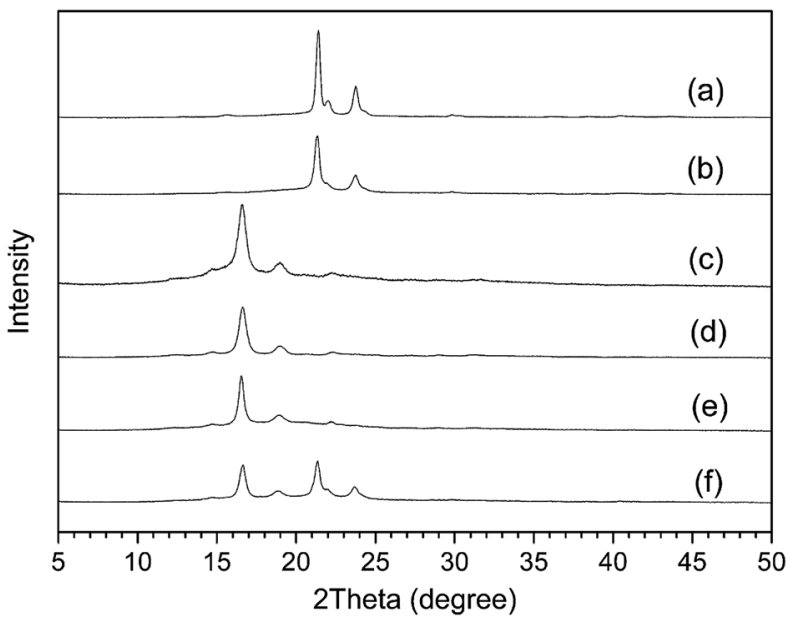

Fig. $14 X$-ray diffraction pattern of synthetic polymers: (a) linear $P C L$, (b) 4sPCL, (c) linear PLLA, (d) 4sPLLA, (e) 4sPCL-b-PLLA, (f) $P C L_{2} P_{2 L A}$

the crystallinity of PCL is obviously better. It can be seen from Fig. 12(f) and 13(f) that crystallization and melting peaks of PLLA segments become wider, indicating that when two PLLA chains and two PCL chains are connected at the same point, the presence of the PCL chain limits the crystallization of the PLLA chain.

Wide-angle X-ray diffraction (WAXD) is another means of observing the crystallization behavior of polymers. Fig. 14 is the WXRD pattern of synthetic polymers. The diffraction peaks of the linear PCL appear at $2 \theta=21.6^{\circ}$ and $23.9^{\circ}$, corresponding to the (110) and (200) faces (Fig. 14(a)). The diffraction peaks of pure PLLA appear at $2 \theta=16.5^{\circ}$ and $19^{\circ}$ (Fig. 14(c)). It can be seen that the characteristic peaks of star homopolymers $4 \mathrm{SPCL}$ and 4sPLLA are similar to the linear polymers, indicating that the star-shaped structure doesn't change the crystalline conformation of polymer chain segments. In addition, it was found that the peak intensity of the star-shaped polymer is all reduced, which proves that the star-shaped structure will reduce the crystallinity of the polymer.

Fig. 14(e) is the X-ray diffraction pattern of the star-block copolymer 4 sPCL- $b$-PLLA. It can be seen that the characteristic peak of the PLLA segment is apparent, but the characteristic diffraction peak of the PCL segment is almost invisible. It shows that the influence of the outer block segment on the movement ability and the crystallization performance of the inner block is still very obvious. Fig. 14(f) is the X-ray diffraction pattern of the miktoarm star-shaped copolymer $\mathrm{PCL}_{2} \mathrm{PLLA}_{2}$. It also shows although the diffraction intensity is reduced, the characteristic diffraction peaks of the PCL and PLLA segments are both obvious. So when the crystalline polymer chains are connected together on the same point, each segment can crystallize and maintain the original crystal conformation, but the existing segment will have some influences on another different segment.

\section{Conclusions}

Well-defined star-shaped polymers with different architectures have been successfully prepared through a combination of one- pot azide-alkyne click chemistry and arm-first method. Several polymer arms containing terminal alkyne groups, including $\mathrm{HC} \equiv \mathrm{C}-\mathrm{PCL}, \quad \mathrm{HC} \equiv \mathrm{C}-\mathrm{PLLA}$ and $\mathrm{HC} \equiv \mathrm{C}$-PCL- $b$-PLLA, were synthesized by ROP. Based on the four azido group small molecule initiator PENTA- $\mathrm{N}_{3}$, four-arm homopolymers 4sPCL and 4sPLLA, four-arm block copolymer 4sPCL- $b$-PLLA and the miktoarm star-shaped copolymer $\mathrm{PCL}_{2} \mathrm{PLLA}_{2}$ were synthesized by click reaction. Merrifield's resin-azide was used to purify the excess arm polymer. The structures of star-shaped polymers are confirmed by NMR, FT-IR and GPC. The melting and crystallization behaviors of these star polymers were investigated by DSC and WXRD. The star-shaped homopolymers 4sPCL and 4sPLLA have lower melting temperature, crystallization temperature, and degree of crystallinity than their linear homologues. To the star-block copolymer 4sPCL- $b$-PLLA, the outer block segment (PLLA) has significant effect on the chain segment movement and crystallization of the inner block segment (PCL). When both PLLA and PCL chains were connected into the core of miktoarm star-shaped copolymer $\mathrm{PCL}_{2} \mathrm{PLLA}_{2}$, the degree of crystallinity of each chain was affected by each other. The DSC and WXRD have confirmed the formation of star-shaped polymers.

\section{Conflicts of interest}

There are no conflicts to declare.

\section{Acknowledgements}

This work was financially supported by the National High-Tech R\&D Program of China (No. 2013AA032202), the National Natural Science Foundation of China (No. 51203118), the Fundamental Research Funds for the Central Universities and the Open Funds for Characterization of Tongji University.

\section{Notes and references}

1 K. Khanna, S. Varshney and A. Kakkar, Polym. Chem., 2010, 1, 1171-1185.

2 W. Wu, W. Wang and J. Li, Prog. Polym. Sci., 2015, 46, 55-85.

3 B. V. K. J. Schmidt, Miktoarm Star Polymers, Royal Society of Chemistry, Cambridge, 2017.

4 S. Cosson, M. Danial, J. R. Saint-Amans and J. J. CooperWhite, Macromol. Rapid Commun., 2017, 38, 1600780.

5 H. A. Zayas, N. P. Truong, D. Valade, Z. Jia and M. J. Monteiro, Polym. Chem., 2013, 4, 592-599.

6 K. Tungala, P. Adhikary, V. Azmeera, K. Kumar, K. Ramesh and S. Krishnamoorthi, RSC Adv., 2016, 6, 41594-41607.

7 J. Hu, R. Qiao, M. R. Whittaker, J. F. Quinn and T. P. Davis, Aust. J. Chem., 2017, 70, 1161-1170.

8 N. Xu, X. Huang, G. Yin, M. Bu, X. Pu, X. Chen, X. Liao and Z. Huang, RSC Adv., 2018, 8, 15604-15612.

9 N. Y. Ahn and M. Seo, RSC Adv., 2016, 6, 47715-47722.

$10 \mathrm{~W}$. Yuan and X. Chen, RSC Adv., 2016, 6, 6802-6810.

11 S. Ito, R. Goseki, T. Ishizone, S. Senda and A. Hirao, Macromolecules, 2013, 46, 819-827. 
12 S. Ito, R. Goseki, T. Ishizone and A. Hirao, Eur. Polym. J., 2013, 49, 2545-2566.

13 T. Tsutsuba, H. Sogawaa and T. Takata, Polym. Chem., 2017, 8, 1445-1448.

14 R. Whitfield, A. Anastasaki, N. P. Truong, B. C. Alexander, O. P. Marta, V. L. Rose, T. A. H. Nguyen, J. A. Burns, S. Perrier, T. P. Davis and D. M. Haddleton, ACS Macro Lett. , 2018, 7, 909-915.

15 M. Dearnley, N. P. Reynolds, P. Cass, X. H. Wei, S. N. Shi, A. A. Mohammed, T. Le, P. Gunatillake, M. L. Tizard, S. H. Thang and T. M. Hinton, Biomacromolecules, 2016, 17, 3532-3578.

16 R. Whitfield, A. Anastasaki, N. P. Truong, P. Wilson, K. Kempe, J. A. Burns, T. P. Davis and D. M. Haddleton, Macromolecules, 2016, 49, 8914-8924.

17 S. Neumann, D. Döhler, D. Ströhl and W. H. Binder, Polym. Chem., 2016, 8, 2342-2351.

18 M. Uchiyama, K. Satoh, T. G. Mckenzie, Q. Fu, G. G. Qiao and M. Kamigaito, Polym. Chem., 2017, 8, 5972-5981.

19 P. Chmielarz, S. Park, A. Sobkowiak and K. Matyjaszewski, Polymer, 2016, 88, 36-42.

20 X. H. Dai, Z. M. Wang, W. Liu, C. M. Dong, J. M. Pan, S. S. Yuan, Y. S. Yan, D. M. Liu and L. Sun, Colloid Polym. Sci., 2014, 292, 2111-2122.

21 G. Y. Shi, X. Z. Tang and C. Y. Pan, J. Polym. Sci., Part A: Polym. Chem., 2010, 46, 2390-2401.

22 G. Y. Shi, L. P. Yang and C. Y. Pan, J. Polym. Sci., Part A: Polym. Chem., 2008, 46, 6496-6508.

23 L. Yang, H. Zhou, G. Shi, Y. Wang and C. Y. Pan, J. Polym. Sci., Part A: Polym. Chem., 2010, 46, 6641-6653.

24 H. Hasegawa, Y. Nagata, K. Terao and M. Suginome, Macromolecules, 2017, 50, 7491-7497.

25 X. Y. Guo, l. Zeng, Z. Wang, T. X. Zhang, C. He and C. Y. Duan, RSC Adv., 2017, 7, 52907-52913.
26 P. Leophairatana, S. Samanta, C. C. D. Silva and J. T. Koberstein, J. Am. Chem. Soc., 2017, 139, 3756.

27 T. Tsutsuba, H. Sogawa and T. Takata, Polym. Chem., 2017, 8, 1445-1448.

28 X. Fan, H. Cheng, X. Wang, E. Ye, J. L. Xian, Y. L. Wu and Z. Li, Adv. Healthcare Mater., 2017, 7, 1701143.

29 N. Cakir, U. Tunca, G. Hizal and H. Durmaz, Macromol. Chem. Phys., 2016, 217, 636-645.

30 A. B. Lowe, Polym. Chem., 2014, 5, 4820-4870.

31 R. Banerjee, S. Maiti and D. Dhara, Green Chem., 2014, 16, 1365-1373.

32 E. Doganci, M. A. Tasdelen and F. Yilmaz, Macromol. Chem. Phys., 2015, 216, 1823-1830.

33 J. Iocozzia, H. Xu, X. Pang, H. Xia, T. Bunning, T. White and Z. Lin, RSC Adv., 2014, 4, 50212-50219.

34 S. Corneillie and M. Smet, Polym. Chem., 2015, 6, 850-867.

35 P. Wang, P. Xu, H. Wei, H. Fang and Y. Ding, J. Appl. Polym. Sci., 2018, 135, 46161.

36 P. Wang, D. Zhang, Y. Zhou, Y. Li, H. Fang, H. Wei and Y. Ding, Ionics, 2018, 24, 787-795.

37 O. Monticelli, M. Calabrese, L. Gardella, A. Fina and E. Gioffredi, Eur. Polym. J., 2014, 58, 69-78.

38 W. M. Stevels, A. Bernard, P. Van De Witte, P. J. Dijkstra and J. Feijen, J. Appl. Polym. Sci., 1996, 62, 1295-1301.

39 I. Navarro-Baena, V. Sessini, F. Dominici, L. Torre, J. M. Kenny and L. Peponi, Polym. Degrad. Stab., 2016, 132, 97-108.

40 A. Ostafinska, I. Fortelny, M. Nevoralova, J. Hodan, J. Kredatusova and M. Slouf, RSC Adv., 2015, 5, 98971-98982.

41 L. Li, B. Lu, Q. Fan, J. Wu, L. Wei, J. Hou, X. Guo and Z. Liu, RSC Adv., 2016, 6, 61630-61640.

42 C. L. Ricardo and P. Tomislav, Isr. J. Chem., 2012, 52, 320327.

43 A. P. Filippov, O. A. Romanova and L. V. Vinogradova, Polym. Sci., 2010, 52, 221-227. 